\title{
Determining hurdle rate and capital allocation in credit portfolio management
}

\author{
Peter Miu \\ McMaster University \\ Bogie Ozdemir \\ Canadian Western Bank \\ Evren Cubukgil \\ Sun Life Financial Group \\ Michael Giesinger \\ Barclays PLC
}

This version: April 2015

\begin{abstract}
:
We examine two interrelated issues in risk-adjusted return on capital performance measurement: estimating hurdle rates and allocating capital to debt instruments in a portfolio. We consider a methodology to differentiate hurdle rates for individual debt instruments that incorporates obligor-specific information. These instrument-specific hurdle rates, which define the required compensation of the shareholders, enable a granular differentiation of systematic risk among debt contracts. Using the proposed approach, we show that the hurdle rate could be materially different among industry sectors and obligors of different credit quality. Profitability assessment could be significantly distorted if the difference in hurdle rates is ignored.
\end{abstract}

JEL classification: G12; G13; G21; G22; G32

Keywords: Credit portfolio management; RAROC; Economic capital; Capital allocation; Hurdle rate; Tail risk 


\section{Introduction}

Economic capital (EC) and risk-adjusted return on capital (RAROC) are two key ingredients of active portfolio management for financial institutions. EC, which commonly referred to as risk capital, captures the risk of the portfolio of assets of the financial institution from its debtholders' perspective. It is typically defined as the critical value of the portfolio loss distribution or the expected shortfall over a one-year risk horizon and at a confidence level corresponding to the target debt rating of the financial institution. It therefore defines the amount of equity capital required to ensure that the target probability of default will not be exceeded. In measuring EC, it is typical to incorporate the diversification effects among the returns of different assets within the portfolio. RAROC, developed by Bankers Trust in the late 1970s, serves as a measure of performance of different assets or lines of business of a financial institution (also see Zaik et al., 1996). It measures the return of the shareholders of the financial institution generated by an asset or a line of business given the required risk capital. A comparison of the shareholders' required rate of return (commonly referred to as the hurdle rate) with RAROC allows a financial institution to find out if an asset or a line of business is creating value for its shareholders. It becomes an indispensible metric to ensure shareholders' value is maximized in formulating deal acceptance/rejection criteria, designing compensation/incentive system, and managing the business mix of a financial institution.

Given that RAROC is measured based on the risk capital (i.e., EC), which is specific to the portfolio composition of the financial institution, different financial institutions can arrive at different risk-adjusted profitability measures for the same asset. For example, a bank having a concentrated loan portfolio in the pharmaceutical sector will arrive at a lower RAROC in 
underwriting a new loan to a pharmaceutical company than another bank with a more diversified portfolio. It therefore violates the classical finance theory in which different agents should arrive at the same ("correct") price for the same asset in a frictionless market where there is no arbitrage opportunity. In such a framework, the risk management function of a financial institution should not have any role to play in capital budgeting. But, in practice, a significant proportion of the portfolio of many financial institutions are either in illiquid assets or in assets that are not tradable at all. Given that the risks of these instruments cannot be easily laid off, their pricing should depend on the financial institutions' (or more precisely its shareholders' and debebtholders') own attitude towards risks, thus providing the underpinning for the use of institution-specific risk capital in capital budgeting. Based on this argument, the conceptual capital budgeting framework developed by Froot and Stein (1998) blends the desirable features of both the classical approach and the RAROC approach with the objective of maximizing shareholders' value.

In this study, we focus on the use of RAROC in credit portfolio management (e.g., managing the corporate debt instruments on the banking book). In practice, there are a couple of issues that may derail the usage of RAROC as a performance measurement tool. The first issue is related to the calculation of risk capital at the portfolio level and how it is allocated to the individual lines of business, sub-portfolios, and/or individual debt instruments constituting these credit portfolios. Value-at-risk (VaR) has been a commonly-used measure for portfolio-level risk capital. To calculate RAROC, we need to allocate this portfolio-level risk capital to different sub-portfolios or individual instruments. Application of the Euler principle in capital allocation is well established (Tasche, 2008; Rosen and Saunders, 2010). It is quite common to allocate the risk capital proportional to each instrument's contribution to the standard deviation of 
the portfolio loss distribution (sometimes referred to as the Risk Contribution methodology). With the help of commonly-used off-the-shelf credit portfolio simulation engines (e.g., Moody's KMV's Porfolio Manager/Risk Frontier), financial institutions can easily accomplish the calculations involved in allocating their economic capital based on the above approach. Although intuitive, there are a couple of problems with this approach. First of all, VaR is not a coherent risk measure (as defined by Artzner et al., 1999), and thus might not provide the correct incentive to manage risk. Second, the Risk Contribution methodology of capital allocation is not directly linked to the tail event that dictates the probability of insolvency of the financial institution which is the main concern of its debtholders. These deficiencies may lead to inconsistent and unintuitive capital allocation results and, in turn, the resulting RAROC measures. To overcome these shortfalls, it is more desirable to use expected shortfall (i.e., tail conditional expectation) instead of VaR to measure portfolio-level capital and to allocate it to individual instruments using what is known in practice as the Tail Risk Allocation methodology. This method directly measures the tail risk of the debt portfolio catering for the risk concerns of the debtholders.

The second issue that may invalidate RAROC as an appropriate performance metric is in the choice of a hurdle rate with which RAROC is compared. Many financial institutions use a single hurdle rate to assess the profitability for all its credit instruments. It may be calculated using the capital asset pricing model (CAPM) and the beta estimated for the financial institution as a whole. It therefore represents the systematic risk of the equity of the financial institution. It can be shown theoretically that the use of a single hurdle rate is only appropriate under very stringent (and unrealistic) distribution assumptions (Milne and Onorato, 2012). Under more realistic market conditions, the use of a single hurdle rate may result in the financial institution 
wrongfully accepting (rejecting) high-risk (low-risk) projects and thus leading to a sub-optimal portfolio composition. As shown by Crouhy et al. (1999) and Milne and Onorato (2012), the economic implications could be significant given plausible parametric assumptions. To rectify this distortion, we need a methodology to determine instrument-specific hurdle rates that can correctly capture the systematic risks of individual debt instruments.

Following the arguments of Crouhy et al. (1999) and Milne and Onorato (2012), we propose a methodology to estimate instrument-specific RAROC hurdle rates that appropriately capture the systematic risks born by the shareholders of the financial institution in underwriting debt contracts to different obligors. Combined with the use of the Tail Risk Allocation methodology mentioned above, the use of differentiated instrument-specific hurdle rates allows us to formulate a RAROC performance metric that caters for the requirements of both the shareholders and debtholders of the financial institution. In adopting this approach, debtholders can rest assured that the probability of insolvency of the financial institution is kept at a low and acceptable level, while at the same time the shareholders of the financial institution can ensure that their values are maximized on a risk-adjusted basis.

In the second part of this paper, we operationalize the proposed methodologies by conducting a RAROC performance measurement exercise with a real-life credit portfolio using tools and information that are readily available to most financial institutions. Specifically, we estimate the instrument-specific hurdle rate for each debt instrument in our portfolio by assessing the systematic risk of the assets of the obligor. We then show how we can incorporate these differentiated hurdle rates to measure the risk-adjusted profitability of individual instruments together with the allocated risk capital from the Tail Risk Allocation methodology. Our results demonstrate the importance of the appropriate use of differentiated RAROC hurdle rates. Based 
on the results of a representative portfolio, we show that the resulting errors in accepting/rejecting a credit exposure and in profitability ranking could be more significant than one would want to ignore if we naively apply a single uniform portfolio-wide hurdle rate in performance assessment.

This study contributes to the literature in the following ways. We start by providing a detailed review of the literature concerning the estimation of RAROC and hurdle rate. With a hypothetical credit portfolio, we then illustrate how a RAROC analysis might be conducted taking into account of the risk consideration of both the shareholders and debtholders of the financial institution. To our knowledge, we are the first to suggest and implement instrumentspecific hurdle rates for RAROC. Our proposed bottom-up approach incorporates the risk perspective of the shareholders into capital allocation through the marginal cost of allocating equity to individual exposures. ${ }^{1}$ We therefore connect the risk perspectives of debtholders and shareholders to establish a dual framework for the capital allocation problem. The former risk perspective refers to the total risk of the portfolio, while the latter is represented by the systematic risk of the debt instruments, to which shareholders are exposed when providing equity to finance individual debt instruments. Unless we are able to differentiate the systematic risk of individual instruments by using instrument-specific hurdle rates, any portfolio management decisions based on marginal RAROC measures will be distorted.

\section{The RAROC framework}

\footnotetext{
${ }^{1}$ The marginal hurdle rate examined in the existing literature (e.g., Stoughton and Zechner, 2007) does not capture the marginal cost of equity based on the systematic risk of individual debt instruments.
} 
In this section, we outline the RAROC framework commonly used in practice to manage corporate loan portfolios. ${ }^{2}$ Consider a portfolio of $n$ loans held by a financial institution (FI). Economic capital (EC) represents the amount of shareholders' capital required to maintain the target debt rating. For example, if the target debt rating of the FI is A and it corresponds to a one-year default probability of 4 basis points, the EC of the FI's loan portfolio is calculated as the loss of this portfolio at the $99.96 \%$ confidence level minus the expected loss of the portfolio. Let us use $E C_{p}$ to denote the economic capital of the overall portfolio $p$ of the FI. We use $E C_{S P_{j}}^{\text {standalone }}$ to denote the risk capital of a sub-portfolio $j(j=1$ to $J$ ) of this FI as if it is held on a stand-alone basis (i.e., without the other sub-portfolios) but evaluated at the same target confidence level. Given the fact that the loss distribution of individual loans are not perfectly correlated, $E C_{p}$ incorporates the portfolio diversification benefit and it is smaller than the sum of the stand-alone risk capitals of all its sub-portfolios:

$$
E C_{p} \leq \sum_{j=1}^{J} E C_{S P_{j}}^{\text {standalone }}
$$

In other words, the risk of insolvency of the FI (i.e., the risk of the FI's debtholders) is reduced given this diversification effect. From the perspective of the FI's shareholders, the reduced capital requirement as a result of the diversification effect will translate into a higher rate of return on equity. To correctly measure the performance of different sub-portfolios, we need to account for this enhancement of profitability by attributing the diversification benefit to each sub-portfolio. It is commonly achieved by allocating the portfolio-level $E C_{p}$ back to each subportfolio $j$ such that the individual allocated capitals $C_{S P_{j}}$ sum up to $E C_{p}$. That is:

\footnotetext{
${ }^{2}$ In this section, although we describe the implementation of the RAROC framework on loan portfolios, the discussion and related methodologies are equally applicable to any credit portfolio that is held by a financial institution in general.
} 


$$
\begin{aligned}
& E C_{p}=\sum_{j=1}^{J} C_{S P_{j}} \\
& C_{S P_{j}}=E C_{p} \frac{\alpha_{S P_{j}}}{\sum_{j=1}^{J} \alpha_{S P_{j}}}
\end{aligned}
$$

in which the sub-portfolio-specific factor $\alpha_{S P_{j}}$ dictates how the capital is allocated. The allocated capital $C_{S P_{j}}$ can then be used as a basis to measure the performance of each subportfolio.

To calculate RAROC of individual loans, we need to allocate the portfolio-level $E C_{p}$ not only to each sub-portfolio but also to each individual loan $i$. Again, we ensure that the allocated capitals $C_{i}$ of individual loans sum up to $E C_{p}$. That is,

$$
E C_{p}=\sum_{i=1}^{n} C_{i}
$$

where

$$
C_{i}=E C_{p} \frac{\alpha_{i}}{\sum_{i=1}^{n} \alpha_{i}}
$$

The loan-specific factor $\alpha_{i}$ therefore defines the adopted capital allocation scheme. There are a number of allocation schemes commonly used in practice, which will be discussed in detail in Section 2.1. With the allocated capital $C_{i}$ and by assuming the cash flows from the loan occurring at a single point in time in the future, we can define the RAROC of loan $i$ as:

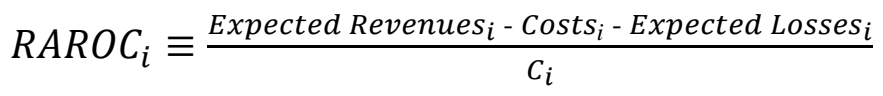

where the numerator is the expected net income of the loan calculated by netting out the costs (e.g., financing costs) and expected loss from the expected revenues generated by the loan. With the RAROC measures of all the loans, we can then assess their profitability by comparing their RAROCs with the required rate of return of the FI's shareholders, usually referred to as the hurdle rate $(h)$. In assessing a new loan, if the RAROC of the loan is higher than the hurdle rate $h$, the loan is deemed to create value for the shareholders and thus it should be granted. On the 
other hand, if its RAROC is below $h$, the loan should be rejected. With the RAROC measures and the hurdle rate, we can also rank the profitability of the loans in our portfolio in terms of the excess return (i.e., $R A R O C_{i}-h$ ) generated by each loan. Such information will be very useful in optimizing the performance of the existing loan portfolio. In practice, it is not uncommon for an FI to use a single institution-wide hurdle rate to assess the profitability of all its loans. A recent survey (Baer et al., 2011) on the use of economic capital in performance management for banks states that "four of the five institutions that impose RAROC hurdles use a single hurdle for all business units, usually the cost of capital of the whole institutions. Only one institution imposes different hurdle rates for different businesses; however, these rates are determined informally and not through systematic analysis. One respondent had attempted to use multiple hurdle rates, but could not get business units to agree on appropriate differentials." In Section 2.2, we argue that the use of a single hurdle rate may distort the profitability measure leading to sub-optimal decision making and we advocate the use of loan-specific hurdle rates.

In the following two sub-sections, we will examine in detail the two key ingredients of the RAROC framework, namely, (a) the estimation and allocation of risk capital (i.e., economic capital); and (b) the choice of RAROC hurdle rate. In doing so, we highlight some of the shortcomings of the current practice and emphasize issues that need to be resolved with the objective of satisfying the risk appetite of the debtholders of the financial institution while at the same time maximizing its shareholders' value.

\subsection{Estimation and allocation of risk capital}

The first step is to find out the portfolio-level economic capital, $E C_{p}$, by calculating the critical value of portfolio loss (e.g., over a one-year risk horizon) at a confidence level (e.g., 
99.96\%) corresponding to the target debt rating (e.g., A) of the FI. To fulfill this objective, it is quite common to use the value-at-risk (VaR) methodology, where for a confidence level $\delta$ (in percent),

$$
V a R_{\delta}=\inf \left\{x \mid \operatorname{Prob}\left[L_{p}>x\right] \geq 1-\frac{\delta}{100}\right\}
$$

where $L_{p}$ is the portfolio loss which follows a known distribution (e.g., obtained by conducting Monte Carlo simulations). VaR is thus the $\delta$-level quantile of the portfolio loss distribution. Based on this approach,

$$
E C_{p}=V a R_{\delta}-\text { Expected loss of portfolio }
$$

The next step is to allocate $E C_{p}$ to individual loans based on a capital allocation scheme defined by loan-specific factor $\alpha_{i}$ (see Equation (3)). There are a number of commonly-used capital allocation schemes. In a market risk setting, one may allocate based on the stand-alone risk capitals. That is,

$$
\alpha_{i}=E C_{i}^{\text {standalone }}
$$

where $E C_{i}^{\text {standalone }}$ is the stand-alone risk capital of asset $i$. Although this approach can be easily implemented to allocate market risk, the notion of the "stand-alone EC" for an individual loan is not sensible given its binary outcomes (i.e., default vs. no default). But this approach can be readily used to allocate to sub-portfolios (e.g., Dhaene et al., 2009) by defining:

$$
\alpha_{S P}=E C_{S P}^{\text {standalone }}
$$

Alternatively, we may adopt the marginal capital allocation principle. In this approach, the allocation is based on the size of the marginal capital, which can be defined as the difference between the portfolio $E C_{p}$ and the EC of the portfolio but with the specific loan (or the specific sub-portfolio) under consideration removed, $E C_{p-i}$. That is, 


$$
\alpha_{i}=E C_{p}-E C_{p-i}
$$

Kimball (1998) proposes the risk contribution methodology to allocate capital among a bank's business units (BUs) based on a concept, which he calls "internal beta", defined as the ratio of the covariance between the return of the business unit $\left(r_{B U_{k}}\right)$ and that of the bank $\left(r_{B a n k}\right)$ to the variance of the bank's return $\left(\sigma_{\text {Bank }}^{2}\right)$. Consider a bank making up of a total of $K$ different BUs $\left(B U_{1}, B U_{2}, \ldots, B U_{k}, \ldots, B U_{K}\right)$. The "internal beta" of $\mathrm{BU} k$ can be expressed as:

$$
\beta_{B U_{k}}=\frac{\operatorname{cov}\left(r_{B U_{k}}, r_{B a n k}\right)}{\sigma_{\text {Bank }}^{2}}
$$

Note that $\sum_{k=1}^{K} \beta_{B U_{k}}=1$ and thus $\beta_{B U_{k}}$ measures the contribution of BU $k$ to the variance of return of the bank (James, 1996, discusses a similar approach regarding the allocation of capital at Bank of America). Using this risk contribution methodology, we can then allocate $E C_{p}$ to different BUs (i.e., sub-portfolios) based on the size of the covariance $\operatorname{cov}\left(r_{B U_{k}}, r_{B a n k}\right)$. That is,

$$
\alpha_{B U_{k}}=\operatorname{cov}\left(r_{B U_{k}}, r_{B a n k}\right)
$$

Thus, the allocated capital of BU $k$ can be expressed as:

$$
C_{B U_{k}}=E C_{p} \frac{\alpha_{B U_{k}}}{\sum_{k=1}^{K} \alpha_{B U_{k}}}=E C_{p} \cdot \beta_{B U_{k}}
$$

By allocating capital based on the contribution to the variance of the overall portfolio return, the risk contribution methodology satisfies a necessary condition of the RAROC framework that is consistent with the model of Froot and Stein (1998). We should not confuse the concept of "internal beta" with the beta in an asset pricing model, like the CAPM, which measures the systematic risk of an asset. By allocating capital using the "internal beta", we have not yet capture the potential difference in systematic risks among different business units (or subportfolios) of the bank. In other words, we have not yet conducted the necessary risk adjustment 
to cater for the fact that shareholders may require different rate of return from different business units (or sub-portfolios) based on their different systematic risks (see, e.g., Wilson, 2003).

The risk contribution methodology can be extended to allocate capital to individual loans in which case it takes the form of:

$$
C_{i}=E C_{p} \frac{\alpha_{i}}{\sum_{i=1}^{n} \alpha_{i}}=E C_{p} \frac{\operatorname{cov}\left(r_{i}, r_{P}\right)}{\sum_{i=1}^{n} \operatorname{cov}\left(r_{i}, r_{P}\right)}=E C_{p} \frac{\operatorname{cov}\left(r_{i}, r_{P}\right)}{\sigma_{P}^{2}}
$$

where $r_{i}$ and $r_{P}$ are the return on loan $i$ and the loan portfolio respectively.

With the help of off-the-shelf credit portfolio simulation engines, FIs can easily calculate the overall portfolio $E C_{p}$ using VaR (i.e., Equations (7) and (8)) and then allocate risk capitals to individual loans following the risk contribution methodology outlined above (i.e., Equations (14a) and (14b)). This approach is commonly used in practice for RAROC calculation and performance evaluation. Although intuitive, there are a couple of shortfalls with the use of the VaR methodology to calculate $E C_{p}$ and the risk contribution methodology for capital allocation. First of all, the VaR approach may not be desirable given the fact that VaR is not a coherent risk measure as defined by Artzner et al. (1999) and thus might not provide the correct incentive to manage risk. Specifically, unless losses are jointly normally distributed, VaR fails to satisfy the axiom of sub-additivity. In other words, we cannot rule out the possibility that the sum of the VaRs of individual assets making up a portfolio is smaller than the VaR of the overall portfolio. It may therefore provide an incentive to disaggregate rather than aggregating risks. For example, an FI may be able to lower its VaR by breaking up its businesses into separate affiliates. It may also create problems in limit management. Controlling the risks of individual assets does not necessarily imply the controlling of the risk of the overall portfolio. For example, if VaR is used to set limits for individual trading desks, there is no guarantee that the chance of realizing a 
portfolio loss that exceeds the sum of the imposed limits is always within the target probability. Given these deficiencies, it is more desirable to use expected shortfall (i.e., tail conditional expectation) instead of VaR to measure portfolio-level capital. Under a continuous loss distribution, the tail conditional expectation (TCE) corresponding to a confidence level $\delta$ (in percent) can be expressed as:

$$
T C E_{\delta}=E\left[L_{p} \mid L_{p} \geq V a R_{\delta}\right]
$$

where $L_{p}$ is the portfolio loss which follows a known distribution. Based on this approach,

$$
E C_{p}=T C E_{\delta}-\text { Expected loss of portfolio }
$$

Unlike VaR, TCE is a coherent risk measure under a continuous loss distribution (Acerbi and Tasche, 2002). It satisfies the axiom of sub-additivity and thus can correctly capture the fact that putting two portfolios together does not create extra risk.

The second shortfall with the conventional approach outlined above lies in the use of risk contribution methodology in allocating risk capital. By allocating capital based on the contribution to the variance of the portfolio loss distribution rather than the critical value at the loss tail of the distribution, we cannot accurately capture the contribution of risk of an asset as perceived by the FI's debtholders. ${ }^{3}$ To illustrate this point, let us consider two positions entered into by a bank, namely a long call option and a short put option on the same underlying. These two positions may contribute equally to the variance of the overall portfolio of the bank (i.e., having the same covariance with the return of the overall portfolio) and thus being allocated identical risk capitals according to the risk contribution methodology. This result is however problematic from the debtholders' perspective because the down-side risk of the short put option

\footnotetext{
${ }^{3}$ Drzik et al. (1998) show that economic capital is a tail risk measure representing the shareholders' equity as the first loss-absorbing tranche protecting the FI's debtholders. This framework can be readily extended to incorporate the notion of protecting the values of policy holders in the setting of an insurance company.
} 
could be much larger than that of the long call option. Thus, the former is expected to contribute more risk to the FI's debtholders at the loss tail of the portfolio loss distribution than the latter. This difference in risk cannot be captured if we use the above risk contribution methodology to allocate risk capital. In addition, other measurement inconsistencies in practice are reported (Kalkbrener et al., 2004). For instance, the allocated capital for a sub-portfolio may be larger than its stand-alone EC. There is also no guarantee that the allocated capital of an instrument is always smaller than its exposure.

To more accurately capture the risk of the debtholders, it is more desirable to use the Tail Risk Allocation methodology, which allocates capital proportional to the loan's contribution to the total portfolio loss at the specified tail-event of the loss distribution. It therefore directly measures the tail risk of the loan portfolio catering for the risk concerns of the debtholders. In this methodology, the total $E C_{p}$ for the portfolio is allocated among the loan contracts based on a loan's average contribution to the portfolio losses within a defined tail region of the portfolio loss distribution. Specifically, the loan-specific allocation factor is defined as the following conditional expectation.

$$
\alpha_{i}=E\left[L_{i} \mid L_{p} \in\left[\operatorname{VaR}_{\delta_{1}}, \operatorname{VaR}_{\delta_{2}}\right]\right]
$$

where $L_{i}$ is the loss attributable to loan $i$, and $L_{p}$ is the portfolio loss. The values, $\delta_{1}$ and $\delta_{2}$, define the specific quantiles of the loss distribution, over which we evaluate the expectation of the loss attributable to loan $i$. In practice, the values of $\delta_{1}$ and $\delta_{2}$ are chosen based on the risk appetite of the FI and its target rating. ${ }^{4}$ By focusing on the loss tail of the distribution, this allocation scheme can accurately capture the contributions of individual loans to the debtholders'

\footnotetext{
${ }^{4}$ However, a recent survey conducted by Mehta et al. (2012) suggests that the choice of confidence level (as defined by $\delta_{1}$ and $\delta_{2}$ ) is becoming less related to risk appetite and target rating subsequent to the recent financial crisis.
} 
risk. The tail risk allocation methodology also has the benefit of satisfying the Euler allocation principle (Tasche, 2008), thus ensuring that the allocated risks naturally add up to the portfoliowide risk and that the axioms for risk allocation methods presented by Kalkbrener (2005) are satisfied. As pointed out by Kalkbrener et al. (2004), the tail risk allocation methodology is linear and diversifying, and thus we can ensure that the allocated capital of a loan will never exceed its exposure.

When $\delta_{2}=100 \%$, the tail risk allocation methodology reduces to the contribution to the expected shortfall. The loan-specific allocation factor therefore becomes:

$$
\alpha_{i}=E\left[L_{i} \mid L_{p} \geq V a R_{\delta_{1}}\right]
$$

In summary, the use of TCE to calculate $E C_{p}$ together with the use of the tail risk allocation methodology to allocate risk capital to individual loans allows us to more accurately capture the risk of the FI's debtholders. This approach is theoretically more desirable than the common practice of using $\mathrm{VaR}$ to calculate $E C_{p}$ and the use of risk contribution methodology to allocate capital. In Section 4, we adopt this approach to conduct a capital allocation exercise on a representative credit portfolio.

\subsection{The choice RAROC hurdle rate}

Another key ingredient of the RAROC framework is the determination of the hurdle rate which represents the required rate of return of FI's shareholders in providing their capital to the FI. If the RAROC of a loan is higher than the hurdle rate $(h)$, the loan is deemed to create value for the shareholders. On the other hand, if its RAROC is below $h$, the loan is considered to be destroying shareholders' value. 
How to choose an appropriate hurdle rate? The most common industry practice is to use a single institution-wide hurdle rate across all business lines within the organization. In terms of its application in managing credit portfolios, the same hurdle rate is typically used to assess the profitability of all the loans. It is quite common to calculate this single hurdle rate using the capital asset pricing model (CAPM) and the beta estimated for the FI as a whole. It therefore represents the systematic risk of the equity of the FI. Crouhy et al. (1999) formalize this idea by proposing an adjusted RAROC, where:

$$
\text { Adjusted RAROC } \equiv \frac{\text { RAROC-r }}{\beta_{E}}
$$

where $r$ is the risk-free rate and $\beta_{E}$ is the beta of the FI's equity. In adopting this adjusted $R A R O C$, the appropriate hurdle rate is simply the market risk premium of the CAPM model. Wilson (2003) asserts that the practice of using a single institution-wide hurdle rate is both theoretically and empirically wrong and presents empirical evidence that shareholders require different hurdle rates for different lines of business (e.g., retail banking, investment banking, etc.) of an FI, even if these businesses are capitalized to a common debt-rating standard. This is consistent with the fact that different lines of business are subject to different amount of systematic risk. For example, an FI's retail banking business is expected to have a lower systematic risk than its investment banking business given that the former is less subject to market-wide risk factors than the latter. Therefore, differentiated costs of equity, and thus hurdle rates, are required to assess the profitability of individual lines of business. By applying Merton's (1974) model to the whole FI, Crouhy et al. (1999) demonstrate how RAROC varies with the volatility and systematic risk of an FI's assets after controlling for its probability of default. Based on plausible parametric assumptions, they show that the economic implications could be significant if the variations of volatility and/or systematic risk are ignored. It may result 
in the FI wrongfully accepting (rejecting) high-risk (low-risk) projects, and thus leading to suboptimal decision making. However, Crouhy et al. do not consider how one can appropriately cater for the systematic risks of individual loan contracts in RAROC performance measurement.

By considering an economy with a unique stochastic discount factor, Milne and Onorato (2012) demonstrate theoretically that the use of a single hurdle rate is only appropriate under very stringent distribution assumptions that could be unrealistic (e.g., asset returns following multivariate normal distribution). They show that, if there are differences in the shape of return distributions of different assets, the return relative to aggregate portfolio risk cannot be optimized by using a single portfolio-wide RAROC hurdle rate. By using the single-factor infinitely granular credit risk model of Vasicek (1987) and the CAPM, they demonstrate that the RAROC hurdle rate is sensitive to the target default threshold of the FI, correlation of obligors' asset returns, credit ratings of the obligors, market risk premium, and the agent's utility function and degree of risk aversion. In particular, the RAROC hurdle rate for a low credit quality (e.g., CCC) loan could be more than several times higher than that for a high credit quality (e.g., A-) loan. However, they do not investigate the impact of other characteristics of the obligors, e.g., their debt levels, financial leverage, industry-specific characteristics, obligor-specific asset correlations, etc., which can also dictate their systematic risks and thus their hurdle rates.

We propose a methodology to estimate instrument-specific RAROC hurdle rates that can correctly capture the systematic risks of individual loans born by the FI's shareholders in underwriting these contracts to different obligors. The hurdle rate is essentially the required rate of return of the FI's shareholders. Suppose $C_{i}$ is amount of capital (i.e., shareholders' equity) allocated to loan $i$ and the required rate of return is denoted by $k_{i}^{E}$, shareholders expect the instrument to generate at least a net dollar value return of $k_{i}^{E} \cdot C_{i}$. In order to maximize the risk- 
adjusted return of the shareholders, the required rate of return $k_{i}^{E}$ should be commensurate with the systematic risk of loan $i$. Thus, $k_{i}^{E}$ is the hurdle rate for loan $i$. If the loan's RAROC is higher than $k_{i}^{E}$, it is adding value to the shareholders. The validity of formulating the required rate of return as a function of the systematic risk exposure of the specific obligor is supported by empirical studies on loan spreads. For example, James and Kizilaslan (2010) find that loan rate is positively associated with both market- and industry-based tail risk measures of the obligor. This is consistent with the notion that commercial banks are in fact taking into consideration of obligors' market and industry risk exposures when pricing individual loan contracts.

We adopt a bottom-up approach by modeling the systematic risk of the debt of each obligor of the FI's loan portfolio. We then use the loan-specific hurdle rate defined by the systematic risk together with the allocated risk capital to formulate a RAROC performance metric that caters for the requirements of both the FI's shareholders and debtholders.

Before we describe the details of the proposed methodology of calculating instrumentspecific hurdle rates (in Section 3), let us examine the relation between the required rate of return and the credit spread of a debt instrument, and how we can potentially extract the implied required rate of return of a debt instrument from its credit spread. Suppose we observe the credit spread $C S_{i, t, \tau}$ of a zero-coupon debt instrument $i$ at time $t$ that matures in $\tau$ periods from today. Suppose we also know the corresponding cumulative probability of default $\left(P D_{i, t, \tau}\right)$ of the obligor and the loss-given-default $\left(L G D_{i}\right)$ of the instrument, which is assumed to be constant over time. We can compute the implied required (continuously compounded) rate of return $k_{i, t, \tau}$ by equating the value of the debt with the discounted value of its expected future payoff.

$$
e^{-\left(r+C S_{i, t, \tau}\right) \cdot \tau}=\left(1-P D_{i, t, \tau} \cdot L G D_{i}\right) \cdot e^{-k_{i, t, \tau} \cdot \tau}
$$




$$
\begin{aligned}
& \Rightarrow k_{i, t, \tau}=r+C S_{i, t, \tau}+\frac{1}{\tau} \ln \left(1-P D_{i, t, \tau} \cdot L G D_{i}\right) \\
& \Rightarrow k_{i, t, \tau} \approx r+C S_{i, t, \tau}-\frac{1}{\tau} P D_{i, t, \tau} \cdot L G D_{i}
\end{aligned}
$$

where $r$ is the risk-free rate, which is assumed to be constant. It should be emphasized that $k_{i, t, \tau}$ is the required rate of return on the loan as an asset held by an investor or an FI in its loan (i.e., asset) portfolio. It is not the rate of return on equity of the FI in holding on to this asset, which we denote as $k_{i}^{E}$. The rate of return on equity $k_{i}^{E}$ is higher than the rate of return on asset $k_{i, t, \tau}$ given that, typically, the FI is not using 100\% equity in underwriting the loan. The former serves as the hurdle rate in the RAROC framework.

The approach of using the market credit spread to calculate the required rate of return might not be workable in practice given the fact that market credit spreads (e.g., based on the spread of credit default swaps or bond yields) are not available for a substantial portion of the debt instruments typically held by FIs. Even if this market information is available for some of the debt instruments, they might not be appropriate for the purpose of credit portfolio management given the difference in liquidity considerations between the debt market and the credit portfolio held by an FI. Trading volume, market-makers' behaviors, the proportion of informed traders versus liquidity traders, and other market-microstructure characteristics of the secondary debt markets dictate the amount of liquidity risk (and potentially liquidity risk premium) being incorporated in market credit spreads. Such liquidity considerations, however, are unlikely to be directly applicable to the credit portfolio of an FI if the portfolio is not held for trading purpose. Lots of debt portfolios of commercial banks and insurance companies are designed to be held to maturity and thus liquidity risk arising from trading activities are irrelevant. Therefore, market credit spread is not the most ideal candidate to be used in 
calculating hurdle rate for the management of these portfolios. In the following section, we propose a methodology of calculating the required rate of return of debt instruments based on pure credit risk consideration and thus will not be contaminated by any liquidity risks.

\section{Proposed instrument-specific required rate of return and hurdle rate based on Merton's model}

We propose an approach to calculate the required rate of return based on Merton's (1974) credit risk model. Consider a defaultable zero-coupon debt $i$ maturing at time $\tau$ from today. Under risk-neutral valuation, it can be shown that its credit spread can be expressed as:

$$
C S_{i, t, \tau}=-\frac{1}{\tau} \ln \left(1-P D_{i, t, \tau}^{Q} \cdot L G D_{i}\right) \approx \frac{1}{\tau} P D_{i, t, \tau}^{Q} \cdot L G D_{i}
$$

where $P D_{i, t, \tau}^{Q}$ is the cumulative risk-neutral probability of default (i.e., under the $Q$-measure) over risk horizon $\tau$. Note that $P D_{i, t, \tau}^{Q}$ is different from $P D_{i, t, \tau}$ in Equation (20). The latter is the physical (i.e., real life) probability of default under the $P$-measure.

Based on the assumptions of Merton's (1974) model, it can be shown that:

$$
P D_{i, t, \tau}^{Q}=\Phi\left[\Phi^{-1}\left(P D_{i, t, \tau}\right)+\frac{\mu_{i}-r}{\sigma_{i}} \sqrt{\tau}\right]
$$

where $\Phi(\boldsymbol{\square})$ is the cumulative standard normal distribution function; and $\mu_{i}$ and $\sigma_{i}$ are respectively the expected return and standard deviation of the asset value of the debt issuer. Based on the capital asset pricing model (CAPM), we have:

$$
\mu_{i}-r=\beta_{i}^{A}\left(R_{m}-r\right)
$$

where $R_{m}$ is the expected market return and $\beta_{i}^{A}$ is the beta of the asset return of debt issuer $i$ with respect to the market. By invoking CAPM and substituting Equation (23) into Equation (22) and in turn into Equation (21), we have: 


$$
C S_{i, t, \tau}=-\frac{1}{\tau} \ln \left\{1-\Phi\left[\Phi^{-1}\left(P D_{i, t, \tau}\right)+\beta_{i}^{A} \frac{R_{m}-r}{\sigma_{i}} \sqrt{\tau}\right] \cdot L G D_{i}\right\}
$$

Based on this model-implied credit spread (of Equation (24)), we can then compute the modelimplied required rate of return $k_{i, t, \tau}$ according to Equation (20). That is,

$$
\begin{aligned}
k_{i, t, \tau}=r- & \frac{1}{\tau} \ln \left\{1-\Phi\left[\Phi^{-1}\left(P D_{i, t, \tau}\right)+\beta_{i}^{A} \frac{R_{m}-r}{\sigma_{i}} \sqrt{\tau}\right] \cdot L G D_{i}\right\}+\frac{1}{\tau} \ln \left(1-P D_{i, t, \tau} \cdot L G D_{i}\right) \\
\approx & r+\frac{1}{\tau}\left\{\Phi\left[\Phi^{-1}\left(P D_{i, t, \tau}\right)+\beta_{i}^{A} \frac{R_{m}-r}{\sigma_{i}} \sqrt{\tau}\right]\right\} \cdot L G D_{i}-\frac{1}{\tau} P D_{i, t, \tau} \cdot L G D_{i} \\
& =r+\frac{1}{\tau}\left\{\Phi\left[\Phi^{-1}\left(P D_{i, t, \tau}\right)+\beta_{i}^{A} \frac{R_{m}-r}{\sigma_{i}} \sqrt{\tau}\right]-P D_{i, t, \tau}\right\} \cdot L G D_{i}
\end{aligned}
$$

Note that $k_{i, t, \tau}$ is the required rate of return for holding on to debt instrument $i$ until maturity date, which is $\tau$ periods from today. It is the required rate of return on the instrument as an asset held by the FI in its portfolio. It is not the required rate of return on the equity of the FI in holding on to this asset, which we denote as $k_{i, t, \tau}^{E}$. The former $\left(k_{i, t, \tau}\right)$ is the return on asset measure of the FI, while the latter $\left(k_{i, t, \tau}^{E}\right)$ is the return on equity measure. The return on equity measure is higher than the return on asset measure given that the exposure is not $100 \%$ equity financed. In practice, most FIs are heavily leveraged. The allocated capital of any debt instrument in the portfolio - representing shareholders' equity - accounts for only a (small) fraction of the credit exposure; the rest of which is financed by debt (or/and deposits) issued by the FI. To find out the required rate of return of the FI's shareholders, we therefore need to account for the additional return the shareholders would require given the higher risk that they are assuming as a result of this financial leverage. Thus, it is $k_{i, t, \tau}^{E}$ rather than $k_{i, t, \tau}$ that serves as the instrument's RAROC hurdle rate.

To conduct the transformation from return on asset to return on equity, we apply the Modigliani-Miller Theorem based on the allocated economic capital of each instrument: 


$$
k_{i}^{E}=k_{i}+\frac{\left(\text { Exposure }_{i}-C_{i}\right)}{C_{i}} \cdot\left(k_{i}-k^{B}\right)
$$

where $C_{i}$ is the allocated economic capital, $\left(\right.$ Exposure $\left._{i}-C_{i}\right)$ is the remaining portion of the credit exposure that is financed by debt issued by the FI, and $k^{B}$ represents the FI's cost of debt. Without loss of generality, we suppress subscripts $t$ and $\tau$ in Equation (26).

It is worthwhile to note that one of the possible obstacles in the implementation of this methodology is the potential lack of market information to calculate the beta $\left(\beta_{i}^{A}\right)$ for the asset return of each obligor in the FI's credit portfolio. For a lot of FIs, many of the debt contracts within their credit portfolios are written to non-publicly traded obligors for which equity and debt data will not be available in estimating asset betas. Nevertheless, for FIs that utilize multifactor models to calculate capital requirements for their credit portfolios, the correlation assumptions between asset returns and market-wide returns required to calculate asset beta are already being made within the economic capital calculation framework itself. By adopting these assumptions consistently in the calculation of asset beta and in turn the hurdle rate via Equations (25) and (26), our proposed methodology is readily applicable even to credit portfolios consisting predominantly of non-publicly traded obligors. To calculate the proposed hurdle rate, an FI, currently utilizing a multifactor model in computing its economic capital, should not require any additional information other than that which has already been used in its economic capital framework. $^{5}$

\footnotetext{
${ }^{5}$ For example, in Moody’s KMV RiskFrontier ${ }^{\circledR}$, which uses the proprietary GCorr ${ }^{\circledR}$ factor model, individual instruments are assigned sector and geographic classifications which together with the instrument's R-squared value are then used to generate correlated asset returns in the simulation of the one-year distribution of portfolio loss. The resulting weighting of the instrument's underlying asset return on the global factor within GCorr ${ }^{\circledR}$ implies a covariance between asset returns and market returns, which can be used to calculate the beta of the instrument's underlying asset.
} 


\section{Demonstration of the proposed methodology}

We operationalize the proposed methodology by conducting a RAROC performance measurement exercise with a real-life credit portfolio using tools and information that are readily available to most financial institutions. We demonstrate how we may conduct capital allocation and arrive at risk-adjusted performance measurements incorporating both the shareholders' and debt-holders' perspective. Three steps are involved in achieving this objective. In the first step (see Section 4.1), we compute the overall economic capital $E C_{p}$ of our portfolio satisfying the risk appetite of the FI's debtholders by making sure that the expected shortfall conforms with the confidence level implicit in its target credit rating. We then allocate this required capital to individual debt instruments using the tail risk allocation methodology. In the second step (see Section 4.2), we compute the required rate of return of each debt instrument in our portfolio following the approach outlined in Section 3. In the last step (see Section 4.3), using the allocated capital from the first step and the required rate of return from the second step, we conduct performance measurements by calculating the required dollar amount net return for each debt instrument. Only if the instruments can generate these required returns can we ensure the FI's shareholders are sufficiently compensated on a risk-adjusted basis. Finally, using indicative market credit spreads, we demonstrate the importance of using instrument-specific hurdle rates in comparing risk-adjusted performances of a subset of the debt instruments in our portfolio.

Before we go through the three steps of our RAROC exercise, let us first briefly describe how we construct our credit portfolio to be used in the rest of this study. Our objective is to come up with a portfolio that resembles a plausible credit portfolio that is held by a large commercial bank operating in North America. We start with the largest 1,000 North American 
public firms by asset values obtained from Compustat as of the end of July 2011. To ensure that we are focusing on firms that are likely to be issuing debts and/or borrowing from banks, we exclude from our sample firms with low debt levels. We also exclude firms with insufficient debt history and incomplete equity return information during the 12 months prior to the end of July 2011. Our final sample includes 785 large publicly-traded firms operating in 38 different industry sectors (see Appendix A, Table A1). We therefore arrive at a sample of potentially the largest corporate debtors from a diverse industry background, which are likely to borrow from commercial banks with different forms of debt instruments (e.g., term loans, corporate bonds).

As of the end of July 2011, we construct a hypothetical, though realistic, credit portfolio for an FI, which underwrites debt instruments to this sample of 785 obligors. In determining the exposure to each of these obligors, we respect the concentration limits typically enforced by an FI. Specifically, the amount of exposure to each obligor is determined based on a three-step process. First, the exposure was set proportional to the total value of the firm's debt outstanding as of end of July 2011 (obtained from Compustat). Next, sectoral maximum exposure limits were applied to each industry sector to ensure that no single industry made up of more than $7 \%$ of the overall exposure of the portfolio. Finally, a single-name concentration limit is applied to ensure that no single entity made up of more than $1 \%$ of the total exposure of the portfolio. Based on this three-step process, the largest exposure obligors, as expected, are primarily financial institutions followed by firms in the Oil \& Gas and the Utilities sectors (see Appendix A Table A2 for a breakdown of portfolio exposure by industry sectors and Table A3 for the top 30 obligors by exposure). The portfolio exposure is predominantly on firms incorporating in the United States (87\%, by exposure), although there are exposures on obligors from ten other countries, including Canada (9\%), Bermuda (2\%), Switzerland (1\%), and the Cayman Islands 
(0.25\%). All of the firms are listed on the stock exchanges of the United States or Canada with assets primarily in North America. In Table 1, we present the summary statistics of the equity values, total asset values, and values of debt outstanding of the 785 firms in our sample. Consistent with the credit risk modeling practice (e.g., the distance-to-default model of Moody's KMV), we present the summary statistics for the full short-term debt plus half long-term debt. In Table 2, we report the exposure and obligor count distribution by credit rating agency grades as of end of July 2011. The portfolio we have constructed is considered to be well-diversified. It is made up of obligors of relatively large firms and of both investment and non-investment grade. ${ }^{6}$ The portfolio has an overall exposure of $\$ 14,778$ million on debts issued by the 785 obligors.

\section{INSERT TABLES 1 AND 2 HERE}

\subsection{Portfolio economic capital and tail-risk capital allocation}

We use a proprietary credit portfolio simulation engine adopted by a bank to calculate the expected shortfall (see Equation (15)) of the portfolio over a one-year risk horizon. The proprietary simulation engine operates in a similar fashion as Moody’s KMV RiskFrontier ${ }^{\circledR}$, which simulates the portfolio loss distribution using Monte Carlo simulation and recognizes the correlation of asset value returns of the obligors within the portfolio (see Moody’s KMV Company, 2007). We adopt a confidence level ( $\delta$ ) of $99.96 \%$, which is considered to be consistent with a target debt rating of A (Jackson et al., 2002). We use the following information specific to each debt instrument of our portfolio:

\footnotetext{
${ }^{6}$ Quite a number of the obligors in our portfolio have relatively low credit rating (e.g., B or below). Although it is quite unlikely that a typical FI will enter into a loan agreement with an obligor of such a low credit rating, we may indeed find lowly-rated obligors in existing credit portfolio of an FI as the financial health of some of the originally credit-worthy obligors has deteriorated due to firm-specific and/or market-wide conditions.
} 
o Probability of default (PD): We use Moody's KMV's one-year expected default frequency (EDF) of the obligors (as of the end of July 2011) to proxy for their one-year probabilities of default;

o Loss-given-default (LGD): Without loss of generality, we assume an LGD of 50\% for all instruments. A 50\% LGD is similar to that documented in the empirical research on the recovery rates of bank loans (e.g., Keisman and Marshella, 2009);

o Exposure-at-default (EAD): We assume all instruments are fully drawn and thus EAD is $100 \%$;

o Exposure of instrument: We use the exposure obtained earlier in this section in constructing our representative portfolio;

o Maturity of contract: We assume a uniform time-to-maturity of one year;

o Cash flow: We assume the instruments are zero-coupon instruments with the payoff of the face value at maturity and no intermediate cash flows;

o Asset return correlation (usually referred to as "R-square"): We use the "R-square" obtained from Moody's KMV's GCorr ${ }^{\circledR}$ model for each obligor as of end of July 2011. The "R-square" measures the correlation of the return on assets of obligors based on a factor model making up of global, regional, and industrial factors (Levy, 2008).

In Table 3, we present the summary statistics of the key input parameters. With the above inputs, the expected shortfall of our portfolio is estimated to be $\$ 1,019$ million by using the proprietary simulation engine and based on the $99.96 \%$ confidence level.

\section{INSERT TABLE 3 HERE}

Capital allocation is performed using again the proprietary simulation engine while adopting the tail risk allocation methodology of Equation (18) with $\delta_{1}$ set at 99.96\%. The largest 
30 obligors by the amount of allocated capital are presented in Table 4 together with their PDs, R-squares, industry sectors, and exposures. In the tail risk allocation approach, capital is allocated based on the contribution to the loss tail, which is primarily driven by the obligors' PDs and R-squares. Not surprisingly, a number of the top thirty obligors (e.g., Nelnet Inc., Community Health Systems Inc., etc) have relatively high PD compared to the average. A majority of the other top obligors have high R-square (e.g., Goldman Sachs Group Inc., Prudential Financial Inc., Metlife Inc., etc). Moreover, as expected, obligors with larger exposures (e.g., Goldman Sachs Group Inc.) are allocated more capital. A total of 18 out of the top 30 obligors are FIs. But there are also obligors from a variety of industry sectors. In Table 5, we show the breakdown of both allocated capital and exposure by industry sectors. Altogether, FIs contribute to $42 \%$ of the overall portfolio EC. Oil \& Gas, Utilities, and Business Service sectors are also well represented, contributing to respectively $9.1 \%, 10.1 \%$, and $4.9 \%$ of the overall EC.

\section{INSERT TABLES 4 AND 5 HERE}

\subsection{Computation of required rate of return}

We compute the required rate of return $k_{i, t, \tau}$ for each debt instrument in our portfolio by using Equation (25). We use the same obligor- and instrument-specific information, namely, PD, LGD, EAD, time-to-maturity, cash flow, and asset return correlation, as used in Section 4.1 in calculating the allocated capital. We obtain the ratio of beta of the asset return and standard deviation of the asset return of each obligor (i.e., $\beta_{i}^{A} / \sigma_{i}$ ) from Moody's KMV's GCorr ${ }^{\circledR}$ (see 
Levy, 2008) as of the end of July $2011 .^{7}$ We assume a market risk premium of $\left(R_{m}-r\right)$ of $6 \%$, which is considered to be consistent with the findings from the analysis on market-implied equity risk premium (e.g., Damodaran, 2012). We also assume a risk-free interest rate $(r)$ of 2\%.

In Table 6, we report the summary statistics of the estimated required rates of return for all obligors (Row 1) and for obligors of different industry sectors. The overall mean (median) of the required rates of return is $2.35 \%$ (2.19\%).

\section{INSERT TABLE 6 HERE}

From Table 6, we observe that obligors from different industries could have very different required rate of returns. In particular, Financial, Oil \& Gas, Telecom, and Metal Products sectors tend to have higher than average required rate of return reflecting the higher systematic risks for these sectors. Nevertheless, based on the standard deviations reported in Table 6, there is significant cross-sectional variation of the required rate of return within each industry sector. It therefore suggests that the required rate of return is not solely determined by the industry effect.

Table 7 presents the statistics of the estimated required rate of return by the obligor's S\&P's credit rating. We also plot the mean value of the estimated required rate of return against credit rating in Figure 1 (which also shows the total amount of exposure in each credit grade). It seems that the credit worthiness of the obligor is a key driver of its required rate of return. In general, the lower the credit rating of the obligor, the higher is its required rate of return. This credit rating effect is considered to be economically significant. For example, the required rates of return for B rated obligors are on average more than 100 basis points higher than those of AA

\footnotetext{
${ }^{7}$ Note that the GCorr model is a multifactor model. As a result, one may argue that the asset beta derived from the GCorr model may not be the same as the asset beta of the CAPM model. For those publicly-traded obligors with valid market information, rather than using the GCorr model, one may conduct her own estimations of beta and standard deviation of asset return of each obligor by adopting a market model.
} 
rated ones. Comparing Table 6 and 7, it seems that the credit rating effect dominates the industry effect in dictating an obligor's required rate of return. Nevertheless, there is still a significant variation of required rates of return across obligors within each credit rating, as manifested in the standard deviations reported in Table 7. This intra-rating variation tends to be higher for lower credit ratings.

\section{INSERT TABLE 7 AND FIGURE 1 HERE}

We conduct a number of sensitivity analyses (results not reported) to gauge the impact of some of the key input parameters on our results. Specifically, we re-run the above analysis using different terms to maturity, risk-free rates, LGDs, and different target debt ratings for the FI. Our key findings and conclusions remain robust. For example, increasing the LGD from 50\% to $75 \%$ results in an increase in the required rates of return for all the instruments. Nevertheless, we still observe the same cross-sectional patterns among different industry sectors and credit ratings as documented in Tables 6 and 7; albeit the cross-sectional differences become more salient. The results of these sensitivity analyses are available from the authors.

\subsection{Hurdle rate and RAROC}

Using the allocated capital obtained in Section 4.1 together with the instrument-specific required rate of return from Section 4.2, we can assess the risk-adjusted performance by calculating the minimum required dollar amount of expected income for each debt instrument in the portfolio. The minimum required expected income from instrument $i$ is simply the sum of the required dollar amount return for shareholders (i.e., $C_{i} \cdot k_{i}^{E}$ ) and the financing cost of the instrument (i.e., $\left(\right.$ Exposure $\left._{i}-C_{i}\right) \cdot k^{B}$ ). Only if the instrument is expected to generate this income can we ensure the FI's shareholders are sufficiently compensated on a risk-adjusted basis. 
We consider a hypothetical FI having the credit portfolio of the 785 debt instruments constructed above as its only assets. Based on the allocated capital calculated in Section 4.1, we compute the RAROC hurdle rate using Equation (26) and then the corresponding minimum required dollar amount of expected income for each of the 785 debt instruments. We report the results for the top 20 obligors by allocated capital in Table $8{ }^{8}$ The weighted average RAROC hurdle rate (weighted by allocated capital) across all the debt instruments is $8.28 \%$.

\section{INSERT TABLE 8 HERE}

To demonstrate the economic significance of using our proposed instrument-specific hurdle rates as opposed to the common practice of using a single portfolio-wide hurdle rate in performance measurement, we conduct an exercise to examine the implications on the decision of accepting/rejecting a debt instrument. We consider 118 debt instruments in our portfolio for which we observe valid one-year CDS spreads (from Bloomberg) as of end of July 2011. Using these market CDS spreads $\left(C S_{i}^{\text {Market }}\right.$ ) to proxy for the one-year credit spreads of these debt instruments, we calculate their RAROC by: ${ }^{9}$

$$
\begin{aligned}
\text { RAROC }_{i} & =\frac{\text { Expected Revenues }_{i}-\text { Costs }_{i}-{\text { Expected } \text { Losses }_{i}}}{C_{i}} \\
& =\frac{\text { Exposure }_{\mathrm{i}} \cdot\left(r_{f}+C S_{i}^{\text {Market }}\right)-\left(\text { Exposure }_{i}-C_{i}\right) \cdot k^{B}-\text { Exposure }_{i} \cdot\left(1+r_{f}+C S_{i}^{\text {Market }}\right) \cdot P D_{i} \cdot L G D_{i}}{C_{i}}
\end{aligned}
$$

\footnotetext{
${ }^{8}$ In evaluating Equation (26), we further assume the cost of debt of the FI $\left(k^{B}\right)$ equals to the risk-free interest rate of $2 \%$. Although short-term funding for an FI is likely to be much more expensive than the risk-free interest rate, the weighted average cost of debt of deposit-taking FIs could be lower and not very different from the risk-free rate given the substantial size of their low-cost deposit bases.

${ }_{9}^{9}$ As discussed earlier in the paper, the observed market CDS spreads account for more than just the credit risk of the debt instruments, as they may contain a significant liquidity premium. Therefore, the expected income implied by the CDS spread is likely to be higher than the true expected income that is solely based on the credit risk of the obligor. As a result, we will tend to overstate the number of instruments having RAROCs that exceed their respective hurdle rates. When implementing the proposed methodology in practice, a financial institution should have all the actual income information of each instrument in its credit portfolio to calculate the RAROC measures.
} 
In calculating RAROC, we assume $k^{B}=r_{f}=2 \%, P D_{i}$ equals to the one-year KMV's EDF of the obligor, and $L G D_{i}=50 \%$. If the resulting RAROC of a debt instrument is higher (lower) than the corresponding instrument-specific hurdle rate from Equation (26), the instrument is deemed creating (destroying) shareholders' values and thus should be accepted (rejected). Based on this acceptance/rejection criteria, 55 (63) out of the 118 loans will be rejected (accepted) because their RAROCs are lower (higher) than the corresponding instrumentspecific hurdle rates. ${ }^{10}$

How will the results be different if we ignore instrument-specific hurdle rates and, like many commonly-used RAROC frameworks, naively use a single uniform hurdle rate as the benchmark in comparing with the RAROC of all the debt instruments? We repeat the above acceptance/rejection checks but now using the weighted average (by allocated capital) hurdle rate of $7.53 \%$ of our sub-portfolio of 118 debt instruments as the single uniform hurdle rate for all the debt instruments. Comparing with the acceptance/rejection results documented previously, this naive RAROC framework results in eight instruments being wrongfully rejected. These eight debt instruments actually contribute positively to shareholders' wealth given the fact that they can generate amounts of expected incomes that exceed the minimum requirements according to their instrument-specific hurdle rates. They are nevertheless rejected in the naive RAROC framework when a single portfolio-wide hurdle rate is applied. The use of the naive

\footnotetext{
${ }^{10}$ An important limitation of RAROC analysis is highlighted in the comparison of the relative performance of instruments. That is, the RAROC of any individual instrument is dependent on the legacy portfolio to which it has been added. For example, a new loan underwritten to an information technology company will attract a higher capital requirement if the existing loan portfolio already has a high concentration on information technology obligors than if the existing portfolio is in fact well diversified. Thus, the RAROC of a new loan and, in turn, whether it will create value for the shareholders of the FI are dictated by the composition of the existing portfolio. Moreover, as removing loans from a portfolio affects the capital requirements of the remaining loans, the results of portfolio management on a RAROC basis can vary depending on the order in which underperforming loans are removed. This is a noteworthy shortcoming of RAROC metrics that deserves further study and investigation. In the present study, we focus on how we may improve the RAROC analysis by introducing differentiated and instrumentspecific hurdle rates.
} 
RAROC framework also results in one instrument being wrongfully accepted, which again results in value destruction for the FI's shareholders. We therefore conclude that the use of the naive framework as opposed to instrument-specific hurdle rates could have a material impact on decision making regarding accepting or rejecting a credit exposure. We cannot maximize the wealth of the FI's shareholders by using a single portfolio-wide hurdle rate.

We conduct a second exercise to gauge the importance of instrument-specific hurdle rates in affecting the rank ordering of the performance of the instruments. We rank the risk-adjusted profitability of the 118 instruments in terms of their excess returns (i.e., $R A R O C_{i}-$ hurdle rate). Table 9 presents the top 20 debt instruments by their excess returns. How will the profitability ranking look like if we naively use a single uniform hurdle rate instead? Table 9 also reports the resulting rankings of the above top 20 debt instruments when we naively use the (capital) weighted average hurdle rate of the 118 instruments as the single portfolio-wide hurdle rate and apply it to all instruments.

\section{INSERT TABLE 9 HERE}

From Table 9, the top 7 instruments by excess return have the same rankings whether instrument-specific or weighted average hurdle rate is used. The rankings of the remaining 13 instruments however could be quite different if a single hurdle rate is used. For example, the credit exposure to Watson Pharmaceuticals Inc., which ranks 13th in terms of profitability will be wrongfully ranked much lower (17th) when the weighted average hurdle rate is used instead.

In Table 10, we present the bottom 20 instruments according to their excess returns based on their instrument-specific hurdle rates. We only consider instruments that still generate positive excess returns. Out of the 118 instruments, only 63 generate positive excess returns based on their hurdle rates. We therefore present the instruments ranked from 44th to 63rd in 
Table 10. We also present in Table 10 the resulting rankings when the weighted average hurdle rate is used as the single portfolio-wide hurdle rate that is applied to all the instruments. Comparing with Table 9, Table 10 provides an even stronger illustration of the implications of applying a single portfolio-wide hurdle rate to those instruments that are close to break even in terms of their profitability. We will not be able to rank them accurately if we apply a single uniform hurdle rate. In fact, eight of these 20 instruments will be wrongfully rejected when the uniform hurdle rate is used given their negative excess returns.

We also conduct a number of sensitivity analyses by using different terms to maturity, risk-free rates, LGDs, and different target debt ratings for the FI. Our key findings and conclusions remain robust. The degree of distortion to the profitability rankings when the single uniform hurdle rate is used instead of the instrument-specific ones is essentially unaffected by these alternative assumptions. The results of these sensitivity analyses are available from the authors.

\section{INSERT TABLE 10 HERE}

In Figure 2, we plot the profitability ranking of each of the instruments based on the naive approach of using the weighted average hurdle rate (vertical axis) against those from using instrument-specific hurdle rate (horizontal axis). The smaller the ranking number, the higher is its profitability in terms of excess return. Those observations above (below) the 45-degree line indicates that applying the uniform hurdle rate in assessing performance understates (overstates) profitability. We observe from Figure 2 that there are quite a number of instruments within the middle range of profitability of which their rankings are either significantly overstated or understated if we ignore the cross-sectional difference in their hurdle rates and naively apply a uniform hurdle rate. 


\section{INSERT FIGURE 2 HERE}

In practice, the uniform hurdle rate applied to the debt instruments of a credit portfolio held by an FI is generally derived with a more subjective approach that may be completely unrelated to even the average characteristic of the portfolio. The findings of the above exercise therefore likely understate the errors resulting from the common practice of using a single institution-wide hurdle rate in assessing profitability. At least, in our naive approach, we use the portfolio weighted average hurdle rate that corresponds to an average instrument within the portfolio. That is, there is still a connection between the characteristics of the portfolio and the uniform hurdle rate being applied. But even that, as demonstrated above, the resulting errors in deciding on accepting/rejecting a credit exposure and in profitability ranking could be more significant than one would want to ignore. Ignoring instrument-specific hurdle rate in the RAROC framework could jeopardize the ability of an FI to achieve its objective of maximizing its shareholders' wealth.

\section{Conclusion}

Based on the structural credit risk model of Merton (1974), we propose a methodology to estimate instrument-specific expected rate of return that can serve as hurdle rate in RAROC performance assessment and dynamic credit portfolio management. By being able to differentiate the systematic risks inherent in debt instruments issued by different obligors, the proposed methodology allows us to more accurately measure the risk-adjusted profitability of the instruments than the RAROC framework typically adopted in practice, where a single uniform portfolio-wide hurdle rate is applied to all the debt instruments. When using the proposed hurdle 
rates together with the economic capital allocated using the tail risk allocation methodology, we establish a RAROC framework that incorporates the risk concerns of both the debtholders and shareholders of financial institutions.

We implement our proposed methodology of calculating instrument-specific hurdle rates on a representative credit portfolio. With obligor-specific information, we demonstrate how we can estimate the hurdle rate for each of the debt instruments in our portfolio. We then show that the decision of accepting/rejecting a credit exposure could be significantly distorted if we ignore the instrument-specific hurdle rate and apply a single uniform hurdle rate to all the instruments. In particular, among the debt instruments under consideration, some that are deemed to create shareholders' value will be wrongfully rejected if the uniform hurdle rate were used as the acceptance benchmark. Naively using this uniform hurdle rate may also result in a distorted profitability ranking of instruments and thus forbids us to maximize the wealth of the shareholders of financial institutions. 


\section{References:}

Acerbi, C., and Tasche, D., 2002. Expected shortfall: A natural coherent alternative to value at risk. Economic Notes 31 (2), 379-388.

Artzner, P., Delbaen, F., Eber, J.-M., and Heath, D., 1999. Coherent measures of risk. Mathematical Finance 9 (3), 203-228.

Baer, T., Mehta, A and Samandari, H., 2011. The use of economic capital in performance management for banks: A perspective. McKinsey \& Company.

Basel Committee on Banking Supervision (BCBS), 2010. Basel III: International framework for liquidity risk measurement, standards and monitoring. Bank for International Settlements.

Crouhy, M., Galai, D., and Mark, R., 2006. The Essentials of Risk Management. McGraw Hill Companies, Inc.

Crouhy, M., Turnbull, S.M., and Wakeman, L.M., 1999. Measuring risk-adjusted performance. Journal of Risk 2 (1), 5-35.

Damodaran, A., 2012. Equity Risk Premiums (ERP): Determinants, Estimation and Implications - the 2012 edition. Working paper, Stern School of Business, http://papers.ssrn.com/sol3/papers.cfm?abstract_id=2027211

Dhaene, J., Tsanakas, A., Valdez, E., and Vanduffel, S., 2009. Optimal Capital Allocation Principles. The $9^{\text {th }}$ International Congress on Insurance: Mathematics and Economics (MIE2005).

Drzik, J., Nakada, P., and Schuermann, T., 1998. The debtholder's perspective: risk, capital, and value measurement in financial institutions - part I. The Journal of Lending \& Credit Risk Management, September 1998.

Froot, K.A., and Stein, J.C., 1998. Risk management, capital budgeting, and capital structure policy for financial institutions: an integrated approach. Journal of Financial Economics 47, 5582.

Jackson, P., Perraudin, W., and Sapporta, V., 2002. Regulatory and “economic” solvency standards for internationally active banks. Journal of Banking and Finance 26, 953-976. 
James, C., 1996. RAROC based capital budgeting and performance evaluation: a case study of bank capital allocation. The Wharton Financial Institutions Center working paper 96-40.

James, C., and Kizilaslan, A., 2010. Asset specificity, industry driven recovery risk and loan pricing. Forthcoming in the Journal of Financial and Quantitative Analysis.

Kalkbrener, M., 2005. An axiomatic approach to capital allocation. Mathematical Finance 15, 425-437.

Kalkbrener, M., Lotter, H., and Overbeck, L., 2004. Sensible and efficient capital allocation for credit portfolios. Risk (January), S19-S24.

Keisman, D. and Marshella, T., 2009. Recoveries on Defaulted Debt In an Era of Black Swans. Moody’s Global Corporate Finance, Moody’s Investments Service.

Kimball, R.C., 1998. Economic Profit and Performance Measurement in Banking. New England Economic Review, July/August 1998, 35-53.

Levy, A., 2008. An Overview of Modeling Credit Portfolios. Moody’s KMV Company.

Merton, R.C., 1974. On the pricing of corporate debt: The risk structure of interest rates. Journal of Finance 29, 449-470.

Mehta, A., Neukirchen, M., Pfetsch, S., and Poppensieker, T., 2012. Managing Market Risk:

Today and Tomorrow. McKinsey Working Papers on Risk, Number 32, McKinsey \& Company.

Milne, A., and Onorato, M., 2012. Risk-adjusted measures of value creation in financial institutions. European Financial Management 18 (4), 578-601.

Moody’s KMV Company, 2007. Why Choose RiskFrontier ${ }^{\mathrm{TM}}$ ?

Rosen, D., and Saunders, D., 2010. Risk factor contributions in portfolio credit risk models. Journal of Banking and Finance 34, 336-349.

Stoughton, N.M., and Zechner, J., 2007. Optimal capital allocation using RAROC and EVA. Journal of Financial Intermediation 16, 312-342.

Tasche, D., 2008. Capital Allocation to Business Units and Sub-Portfolios: The Euler Principle. In Resti, A. (Ed.), Pillar II in the new Basel Accord: The Challenge of Economic Capital. Risk Books, London, pp.423-453. 
Vasicek, O., 1987. Probability of loss on loan portfolio. KMV Corporation.

Wilson, T., 2003. Overcoming the hurdle. Risk, July 2003, 79-83.

Zaik, E., Walter, J., Kelling, G., and James, C., 1996. RAROC at Bank of America: From theory to practice. Journal of Applied Corporate Finance 9 (2), 83-93. 
Table 1: Summary statistics of equity value, asset value, and debt value of the 785 obligors.

\begin{tabular}{|l|c|c|c|}
\hline & Equity (\$M) & Asset Value (\$M) & $\begin{array}{c}\text { Full Short-Term Debt plus } \\
\text { Half Long-Term Debt (\$M) }\end{array}$ \\
\hline Median & 2,452 & 3,821 & 927 \\
\hline Average & 7,457 & 14,535 & 7,151 \\
\hline Minimum & 242 & 503 & 1.0 \\
\hline Maximum & 183,039 & 985,136 & 845,775 \\
\hline Std. Dev. & 15,186 & 54,271 & 45,584 \\
\hline
\end{tabular}


Table 2: Exposure and obligor count distribution by credit rating agency grades (as of end of July 2011)

\begin{tabular}{|c|r|r|r|r|r|}
\hline \multicolumn{3}{|c|}{ S\&P's Ratings } & \multicolumn{3}{c|}{ Moody's Ratings } \\
\hline Rating & Exposure Percent & Count Percent & Rating & Exposure Percent & Count Percent \\
\hline AAA & $0.4 \%$ & $0.1 \%$ & Aaa & $0.8 \%$ & $0.3 \%$ \\
\hline AA & $3.5 \%$ & $1.5 \%$ & Aa & $2.0 \%$ & $0.8 \%$ \\
\hline A & $14.2 \%$ & $7.4 \%$ & A & $12.2 \%$ & $6.4 \%$ \\
\hline BBB & $34.4 \%$ & $25.1 \%$ & Baa & $26.7 \%$ & $18.6 \%$ \\
\hline BB & $13.9 \%$ & $14.7 \%$ & Ba & $10.8 \%$ & $10.2 \%$ \\
\hline B & $6.9 \%$ & $7.5 \%$ & B & $1.0 \%$ & $11.7 \%$ \\
\hline CCC-C & $0.2 \%$ & $0.5 \%$ & Caa-C & $35.4 \%$ & $1.4 \%$ \\
\hline Unrated & $26.5 \%$ & $43.2 \%$ & Unrated & & $50.8 \%$ \\
\hline
\end{tabular}


Table 3: Summary statistics of key input parameters of the debt instruments.

\begin{tabular}{|l|c|c|c|}
\hline & R-square & PD & Exposure (\$M) \\
\hline Median & 0.228 & $0.23 \%$ & 15.2 \\
\hline Average & 0.237 & $0.74 \%$ & 18.6 \\
\hline Minimum & 0.100 & $0.01 \%$ & 1.0 \\
\hline Maximum & 0.650 & $35.0 \%$ & 130.7 \\
\hline Std. Dev. & 0.084 & $1.72 \%$ & 13.0 \\
\hline
\end{tabular}


Table 4: The largest 30 obligors by allocated capital

\begin{tabular}{|c|c|c|c|c|c|c|c|}
\hline Identifier & Counterparty Name & PD & R-square & Industry & Exposure & $\begin{array}{c}\text { Capital } \\
\text { ES } \\
99.96 \% \\
\end{array}$ & $\begin{array}{c}\text { Capital } \\
(\%)\end{array}$ \\
\hline GS & GOLDMAN SACHS GROUP INC & $0.22 \%$ & 0.65 & Non-Bank FI & 130.68 & 25.26 & $2.48 \%$ \\
\hline BNS & BANK OF NOVA SCOTIA & $0.42 \%$ & 0.59 & Commercial Bank & 99.46 & 24.93 & $2.45 \%$ \\
\hline TD & TORONTO DOMINION BANK & $0.25 \%$ & 0.59 & Commercial Bank & 99.46 & 20.28 & $1.99 \%$ \\
\hline PRU & PRUDENTIAL FINANCIAL INC & $2.59 \%$ & 0.65 & Insurance & 38.65 & 14.13 & $1.39 \%$ \\
\hline WFC & WELLS FARGO \& CO & $0.39 \%$ & 0.54 & Commercial Bank & 99.46 & 14.09 & $1.38 \%$ \\
\hline MET & METLIFE INC & $2.68 \%$ & 0.60 & Insurance & 38.65 & 13.76 & $1.35 \%$ \\
\hline AFL & AFLAC INC & $0.88 \%$ & 0.42 & Insurance & 74.08 & 13.36 & $1.31 \%$ \\
\hline NNI & NELNET INC & $35.00 \%$ & 0.33 & Financial Services & 43.25 & 11.89 & $1.17 \%$ \\
\hline $\mathrm{CNO}$ & CNO FINANCIAL GROUP INC & $2.23 \%$ & 0.43 & Insurance & 47.22 & 11.56 & $1.13 \%$ \\
\hline FFG & FBL FINANCIAL GROUP INC-CL A & $3.93 \%$ & 0.44 & Insurance & 35.05 & 10.03 & $0.98 \%$ \\
\hline UAL & UNITED CONTINENTAL HLDGS INC & $2.59 \%$ & 0.35 & Air Transport & 52.46 & 9.85 & $0.97 \%$ \\
\hline EIX & EDISON INTERNATIONAL & $0.80 \%$ & 0.55 & Utilities & 39.74 & 9.17 & $0.90 \%$ \\
\hline SNV & SYNOVUS FINANCIAL CORP & $3.28 \%$ & 0.38 & Commercial Bank & 41.06 & 8.86 & $0.87 \%$ \\
\hline NDAQ & NASDAQ OMX GROUP INC & $5.84 \%$ & 0.17 & Non-Bank FI & 41.16 & 8.43 & $0.83 \%$ \\
\hline AIZ & ASSURANT INC & $1.76 \%$ & 0.41 & Insurance & 43.82 & 8.39 & $0.82 \%$ \\
\hline CMS & CMS ENERGY CORP & $1.76 \%$ & 0.51 & Utilities & 30.98 & 8.38 & $0.82 \%$ \\
\hline AXP & AMERICAN EXPRESS CO & $0.15 \%$ & 0.49 & Financial Services & 97.63 & 8.36 & $0.82 \%$ \\
\hline $\mathrm{FE}$ & FIRSTENERGY CORP & $0.58 \%$ & 0.53 & Utilities & 45.45 & 7.92 & $0.78 \%$ \\
\hline $\mathrm{X}$ & UNITED STATES STEEL CORP & $4.80 \%$ & 0.32 & Metal Products & 30.84 & 7.78 & $0.76 \%$ \\
\hline MFC & MANULIFE FINANCIAL CORP & $0.54 \%$ & 0.65 & Insurance & 38.65 & 7.59 & $0.74 \%$ \\
\hline $\mathrm{S}$ & SPRINT NEXTEL CORP & $2.44 \%$ & 0.30 & Telecoms & 48.54 & 6.56 & $0.64 \%$ \\
\hline $\mathrm{CYH}$ & COMMUNITY HEALTH SYSTEMS INC & $6.12 \%$ & 0.22 & Medical Services & 32.46 & 6.18 & $0.61 \%$ \\
\hline IVR & INVESCO MORTGAGE CAPITAL INC & $3.04 \%$ & 0.11 & Funds & 36.99 & 6.17 & $0.61 \%$ \\
\hline ICE & INTERCONTINENTALEXCHANGE INC & $2.27 \%$ & 0.14 & Non-Bank FI & 57.54 & 6.09 & $0.60 \%$ \\
\hline SHLD & SEARS HOLDINGS CORP & $1.72 \%$ & 0.28 & Retail \& Wholesale & 40.86 & 5.96 & $0.59 \%$ \\
\hline SHAW & SHAW GROUP INC & $5.02 \%$ & 0.25 & Business Service & 27.79 & 5.86 & $0.57 \%$ \\
\hline AEP & AMERICAN ELECTRIC POWER CO & $0.27 \%$ & 0.55 & Utilities & 45.29 & 5.79 & $0.57 \%$ \\
\hline ORI & OLD REPUBLIC INTL CORP & $1.23 \%$ & 0.39 & Insurance & 34.09 & 5.53 & $0.54 \%$ \\
\hline BXS & BANCORPSOUTH INC & $2.81 \%$ & 0.39 & Commercial Bank & 30.31 & 5.50 & $0.54 \%$ \\
\hline $\mathrm{BDN}$ & BRANDYWINE REALTY TRUST & $2.68 \%$ & 0.35 & Funds & 26.04 & 5.50 & $0.54 \%$ \\
\hline \multicolumn{5}{|c|}{ All Other Exposure } & $13,230.31$ & 715.99 & $70.25 \%$ \\
\hline \multicolumn{5}{|c|}{ Total } & $14,777.99$ & $1,019.17$ & $100.00 \%$ \\
\hline
\end{tabular}


Table 5: Capital allocation by industry sector

\begin{tabular}{|c|c|c|c|c|}
\hline Sector & $\begin{array}{c}\text { Exposure } \\
\text { (\$ million) }\end{array}$ & $\begin{array}{c}\text { Exposure } \\
\text { (\%) }\end{array}$ & $\begin{array}{l}\text { Allocated capital } \\
\text { (\$ million) }\end{array}$ & $\begin{array}{c}\text { Allocated } \\
\text { capital (\%) }\end{array}$ \\
\hline Financial Sector & $3,978.24$ & $26.92 \%$ & 430.97 & $42.29 \%$ \\
\hline Commercial Bank & $1,128.00$ & $7.63 \%$ & 122.71 & $12.04 \%$ \\
\hline Funds & $1,049.20$ & $7.10 \%$ & 82.14 & $8.06 \%$ \\
\hline Insurance & $1,034.69$ & $7.00 \%$ & 143.16 & $14.05 \%$ \\
\hline Non-Bank FI & 529.75 & $3.58 \%$ & 58.69 & $5.76 \%$ \\
\hline Financial Services & 236.60 & $1.60 \%$ & 24.27 & $2.38 \%$ \\
\hline Business Service & $1,292.12$ & $8.74 \%$ & 50.29 & $4.93 \%$ \\
\hline Oil \& Gas & $1,320.50$ & $8.94 \%$ & 92.41 & $9.07 \%$ \\
\hline Oil \& Gas, Exploration & $1,036.79$ & $7.02 \%$ & 74.25 & $7.29 \%$ \\
\hline Oil \& Gas, Refining & 283.70 & $1.92 \%$ & 18.16 & $1.78 \%$ \\
\hline Utilities & $1,199.50$ & $8.12 \%$ & 103.21 & $10.13 \%$ \\
\hline Chemicals & 811.04 & $5.49 \%$ & 24.63 & $2.42 \%$ \\
\hline Retail \& Wholesale & 747.99 & $5.06 \%$ & 32.70 & $3.21 \%$ \\
\hline Consumer Durables & 562.10 & $3.80 \%$ & 30.57 & $3.00 \%$ \\
\hline Aerospace \& Defence & 554.66 & $3.75 \%$ & 10.62 & $1.04 \%$ \\
\hline Telecoms & 479.58 & $3.25 \%$ & 30.39 & $2.98 \%$ \\
\hline Automotive & 455.56 & $3.08 \%$ & 29.44 & $2.89 \%$ \\
\hline Equipment & 447.67 & $3.03 \%$ & 21.27 & $2.09 \%$ \\
\hline Machinery \& Equipment & 442.97 & $3.00 \%$ & 27.49 & $2.70 \%$ \\
\hline Rail \& Water Transportation & 314.57 & $2.13 \%$ & 21.73 & $2.13 \%$ \\
\hline Food Manufacturing & 312.12 & $2.11 \%$ & 8.01 & $0.79 \%$ \\
\hline Metal Products & 289.95 & $1.96 \%$ & 26.48 & $2.60 \%$ \\
\hline Paper Products & 180.66 & $1.22 \%$ & 6.55 & $0.64 \%$ \\
\hline Medical Services & 170.54 & $1.15 \%$ & 9.90 & $0.97 \%$ \\
\hline Mining & 168.73 & $1.14 \%$ & 8.60 & $0.84 \%$ \\
\hline Construction & 162.59 & $1.10 \%$ & 13.84 & $1.36 \%$ \\
\hline Entertainment & 131.48 & $0.89 \%$ & 6.11 & $0.60 \%$ \\
\hline Real Estate & 119.96 & $0.81 \%$ & 5.13 & $0.50 \%$ \\
\hline Hotels \& Restaurants & 114.16 & $0.77 \%$ & 2.95 & $0.29 \%$ \\
\hline Land Transport & 96.01 & $0.65 \%$ & 2.24 & $0.22 \%$ \\
\hline Air Transport & 95.65 & $0.65 \%$ & 12.16 & $1.19 \%$ \\
\hline Clothing Manufacturing & 87.74 & $0.59 \%$ & 2.95 & $0.29 \%$ \\
\hline Consumer Services & 64.69 & $0.44 \%$ & 3.66 & $0.36 \%$ \\
\hline Agriculture & 46.20 & $0.31 \%$ & 1.67 & $0.16 \%$ \\
\hline Automotive Rental & 40.00 & $0.27 \%$ & 1.53 & $0.15 \%$ \\
\hline Publishing & 36.77 & $0.25 \%$ & 0.55 & $0.05 \%$ \\
\hline Food Retail \& Wholesale & 23.51 & $0.16 \%$ & 0.30 & $0.03 \%$ \\
\hline Forestry & 19.01 & $0.13 \%$ & 0.71 & $0.07 \%$ \\
\hline Tobacco & 11.73 & $0.08 \%$ & 0.10 & $0.01 \%$ \\
\hline Total & $14,777.99$ & $100.00 \%$ & $1,019.17$ & $100.00 \%$ \\
\hline
\end{tabular}


Table 6: Estimated required rate of return by sector

\begin{tabular}{|c|c|c|c|c|}
\hline Sector & $\begin{array}{c}\text { No. of } \\
\text { observations }\end{array}$ & Mean & Median & $\begin{array}{l}\text { Standard } \\
\text { Deviation }\end{array}$ \\
\hline All obligors & 785 & $2.35 \%$ & $2.19 \%$ & $0.54 \%$ \\
\hline \multicolumn{5}{|l|}{ Financial Sector } \\
\hline Commercial Bank & 33 & $2.46 \%$ & $2.36 \%$ & $0.41 \%$ \\
\hline Funds & 60 & $2.36 \%$ & $2.24 \%$ & $0.36 \%$ \\
\hline Insurance & 32 & $2.74 \%$ & $2.51 \%$ & $0.68 \%$ \\
\hline Non-Bank FI & 17 & $2.51 \%$ & $2.30 \%$ & $0.64 \%$ \\
\hline Financial Services & 6 & $3.12 \%$ & $2.17 \%$ & $2.42 \%$ \\
\hline Business Service & 99 & $2.22 \%$ & $2.11 \%$ & $0.39 \%$ \\
\hline \multicolumn{5}{|l|}{ Oil \& Gas } \\
\hline Oil \& Gas, Exploration & 60 & $2.53 \%$ & $2.33 \%$ & $0.58 \%$ \\
\hline Oil \& Gas, Refining & 8 & $2.30 \%$ & $2.24 \%$ & $0.18 \%$ \\
\hline Chemicals & 49 & $2.17 \%$ & $2.11 \%$ & $0.24 \%$ \\
\hline Utilities & 46 & $2.30 \%$ & $2.20 \%$ & $0.28 \%$ \\
\hline Aerospace \& Defence & 41 & $2.10 \%$ & $2.07 \%$ & $0.07 \%$ \\
\hline Retail \& Wholesale & 38 & $2.29 \%$ & $2.14 \%$ & $0.49 \%$ \\
\hline Consumer Durables & 36 & $2.32 \%$ & $2.23 \%$ & $0.30 \%$ \\
\hline Equipment & 31 & $2.26 \%$ & $2.18 \%$ & $0.23 \%$ \\
\hline $\begin{array}{l}\text { Machinery \& } \\
\text { Equipment }\end{array}$ & 31 & $2.36 \%$ & $2.20 \%$ & $0.50 \%$ \\
\hline Telecoms & 20 & $2.56 \%$ & $2.19 \%$ & $0.81 \%$ \\
\hline Automotive & 20 & $2.44 \%$ & $2.22 \%$ & $0.51 \%$ \\
\hline Metal Products & 20 & $2.63 \%$ & $2.32 \%$ & $0.96 \%$ \\
\hline Mining & 17 & $2.24 \%$ & $2.19 \%$ & $0.23 \%$ \\
\hline Other & 121 & $2.33 \%$ & $2.17 \%$ & $0.62 \%$ \\
\hline
\end{tabular}


Table 7: Estimated required rate of return by obligor's S\&P's credit grade

\begin{tabular}{|c|c|c|c|c|}
\hline & $\begin{array}{c}\text { No. of } \\
\text { observations }\end{array}$ & Mean & Median & $\begin{array}{c}\text { Standard } \\
\text { Deviation }\end{array}$ \\
\hline AAA & 1 & $2.20 \%$ & $2.20 \%$ & $\mathrm{n} / \mathrm{a}$ \\
\hline AA+ & 0 & $\mathrm{n} / \mathrm{a}$ & $\mathrm{n} / \mathrm{a}$ & $\mathrm{n} / \mathrm{a}$ \\
\hline AA & 3 & $2.08 \%$ & $2.06 \%$ & $0.05 \%$ \\
\hline AA- & 9 & $2.22 \%$ & $2.07 \%$ & $0.26 \%$ \\
\hline A+ & 9 & $2.13 \%$ & $2.16 \%$ & $0.05 \%$ \\
\hline A & 20 & $2.26 \%$ & $2.13 \%$ & $0.55 \%$ \\
\hline A- & 29 & $2.32 \%$ & $2.17 \%$ & $0.47 \%$ \\
\hline BBB+ & 49 & $2.25 \%$ & $2.19 \%$ & $0.20 \%$ \\
\hline BBB & 75 & $2.33 \%$ & $2.21 \%$ & $0.36 \%$ \\
\hline BBB- & 67 & $2.44 \%$ & $2.27 \%$ & $0.48 \%$ \\
\hline BB+ & 31 & $2.32 \%$ & $2.22 \%$ & $0.32 \%$ \\
\hline BB & 36 & $2.38 \%$ & $2.24 \%$ & $0.41 \%$ \\
\hline BB- & 37 & $2.74 \%$ & $2.37 \%$ & $0.87 \%$ \\
\hline B+ & 30 & $2.77 \%$ & $2.58 \%$ & $0.82 \%$ \\
\hline B & 25 & $3.11 \%$ & $2.81 \%$ & $1.08 \%$ \\
\hline B- & 2 & $4.76 \%$ & $4.76 \%$ & $0.19 \%$ \\
\hline CCC+ & 3 & $5.04 \%$ & $4.32 \%$ & $2.74 \%$ \\
\hline Unrated & 359 & $2.21 \%$ & $2.13 \%$ & $0.25 \%$ \\
\hline
\end{tabular}


Table 8: Estimated RAROC hurdle rates and the minimum required dollar amounts of expected income for the top 20 obligors by allocated capital

\begin{tabular}{|l|c|r|r|}
\hline \multicolumn{1}{|c|}{ Name } & Ticker & \multicolumn{1}{c|}{$\begin{array}{c}\text { RAROC } \\
\text { hurdle rate }\end{array}$} & Required income (\$) \\
\hline GOLDMAN SACHS GROUP INC & GS & $4.33 \%$ & $3,201,190$ \\
\hline BANK OF NOVA SCOTIA & BNS & $4.79 \%$ & $2,684,665$ \\
\hline TORONTO DOMINION BANK & TD & $4.29 \%$ & $2,454,492$ \\
\hline PRUDENTIAL FINANCIAL INC & PRU & $8.89 \%$ & $1,745,956$ \\
\hline WELLS FARGO \& CO & WFC & $5.32 \%$ & $2,456,725$ \\
\hline METLIFE INC & MET & $9.01 \%$ & $1,736,834$ \\
\hline AFLAC INC & AFL & $6.79 \%$ & $2,121,605$ \\
\hline NELNET INC & NNI & $24.07 \%$ & $3,490,103$ \\
\hline CNO FINANCIAL GROUP INC & CNO & $9.03 \%$ & $1,756,885$ \\
\hline FBL FINANCIAL GROUP INC-CL A & FFG & $10.71 \%$ & $1,574,690$ \\
\hline UNITED CONTINENTAL HLDGS INC & UAL & $10.42 \%$ & $1,878,891$ \\
\hline EDISON INTERNATIONAL & EIX & $6.15 \%$ & $1,175,403$ \\
\hline SYNOVUS FINANCIAL CORP & SNV & $10.61 \%$ & $1,584,521$ \\
\hline NASDAQ OMX GROUP INC & NDAQ & $13.66 \%$ & $1,805,530$ \\
\hline ASSURANT INC & AIZ & $8.80 \%$ & $1,446,979$ \\
\hline CMS ENERGY CORP & CMS & $7.97 \%$ & $1,119,811$ \\
\hline AMERICAN EXPRESS CO & AXP & $4.73 \%$ & $2,180,940$ \\
\hline FIRSTENERGY CORP & FE & $5.89 \%$ & $1,217,012$ \\
\hline UNITED STATES STEEL CORP & X & $12.08 \%$ & $1,401,282$ \\
\hline MANULIFE FINANCIAL CORP & MFC & $5.65 \%$ & $1,049,979$ \\
\hline TOTAL PORTFOLIO & & $\mathbf{8 . 2 8 \%}$ & $\mathbf{3 5 9 , 5 3 9 , 4 8 1}$ \\
\hline
\end{tabular}


Table 9: Top 20 debt instruments by profitability ranking: Instrument-specific hurdle rate vs. uniform hurdle rate

\begin{tabular}{|c|l|c|c|c|c|}
\hline \multirow{2}{*}{ Ticker } & \multicolumn{2}{|c|}{ Name } & \multicolumn{2}{c|}{$\begin{array}{c}\text { Using instrument-specific } \\
\text { hurdle rate }\end{array}$} & $\begin{array}{c}\text { Using (uniform) weighted } \\
\text { average hurdle rate }\end{array}$ \\
\cline { 3 - 6 } & & \multicolumn{2}{|c|}{} & & \\
\cline { 3 - 6 } & & Ranking & Excess return & Ranking & Excess return \\
\hline SXT & SENSIENT TECHNOLOGIES CORP & 1 & $74.40 \%$ & 1 & $72.93 \%$ \\
\hline CVH & COVENTRY HEALTH CARE INC & 2 & $39.29 \%$ & 2 & $42.03 \%$ \\
\hline RL & RALPH LAUREN CORP & 3 & $37.08 \%$ & 3 & $36.32 \%$ \\
\hline CVG & CONVERGYS CORP & 4 & $34.90 \%$ & 4 & $34.66 \%$ \\
\hline DGX & QUEST DIAGNOSTICS INC & 5 & $31.87 \%$ & 5 & $31.71 \%$ \\
\hline FIS & FIDELITY NATIONAL INFO SVCS & 6 & $30.44 \%$ & 6 & $28.77 \%$ \\
\hline HPT & HOSPITALITY PROPERTIES TRUST & 7 & $28.46 \%$ & 7 & $26.99 \%$ \\
\hline CL & COLGATE-PALMOLIVE CO & 8 & $24.24 \%$ & 10 & $21.96 \%$ \\
\hline UVV & UNIVERSAL CORP/VA & 9 & $23.66 \%$ & 9 & $24.48 \%$ \\
\hline HRB & BLOCK H \& R INC & 10 & $22.39 \%$ & 8 & $24.84 \%$ \\
\hline RKT & ROCK-TENN CO & 11 & $21.14 \%$ & 12 & $20.56 \%$ \\
\hline A & AGILENT TECHNOLOGIES INC & 12 & $20.51 \%$ & 14 & $19.17 \%$ \\
\hline WPI & WATSON PHARMACEUTICALS INC & 13 & $19.22 \%$ & 17 & $16.92 \%$ \\
\hline DF & DEAN FOODS CO & 14 & $18.75 \%$ & 11 & $20.66 \%$ \\
\hline G & GENPACT LTD & 15 & $18.20 \%$ & 15 & $18.35 \%$ \\
\hline WEN & WENDY'S CO & 16 & $17.16 \%$ & 13 & $19.62 \%$ \\
\hline EQY & EQUITY ONE INC & 17 & $16.70 \%$ & 18 & $16.48 \%$ \\
\hline CPB & CAMPBELL SOUP CO & 18 & $16.50 \%$ & 19 & $15.47 \%$ \\
\hline DAR & DARLING INTERNATIONAL INC & 19 & $15.99 \%$ & 16 & $17.21 \%$ \\
\hline DDS & DILLARDS INC -CL A & 20 & $15.12 \%$ & 20 & $14.66 \%$ \\
\hline
\end{tabular}


Table 10: Bottom 20 debt instruments by profitability ranking: Instrument-specific hurdle rate vs. uniform hurdle rate

\begin{tabular}{|c|c|c|c|c|c|}
\hline \multirow{2}{*}{ Ticker } & \multirow{2}{*}{ Name } & \multicolumn{2}{|c|}{$\begin{array}{l}\text { Using instrument- } \\
\text { specific hurdle rate }\end{array}$} & \multicolumn{2}{|c|}{$\begin{array}{l}\text { Using (uniform) weighted } \\
\text { average hurdle rate }\end{array}$} \\
\hline & & Ranking & Excess return & Ranking & Excess return \\
\hline KMP & KINDER MORGAN ENERGY -LP & 44 & $4.30 \%$ & 53 & $0.68 \%$ \\
\hline $\mathrm{HCP}$ & HCP INC & 45 & $3.85 \%$ & 45 & $2.42 \%$ \\
\hline SPLS & STAPLES INC & 46 & $3.74 \%$ & 44 & $2.52 \%$ \\
\hline OKS & ONEOK PARTNERS -LP & 47 & $3.57 \%$ & 52 & $0.91 \%$ \\
\hline DOV & DOVER CORP & 48 & $3.51 \%$ & 49 & $1.55 \%$ \\
\hline WMT & WAL-MART STORES INC & 49 & $3.46 \%$ & 55 & $0.51 \%$ \\
\hline BEAM & BEAM INC & 50 & $3.43 \%$ & 46 & $1.96 \%$ \\
\hline GLW & CORNING INC & 51 & $3.30 \%$ & 39 & $3.07 \%$ \\
\hline WRB & BERKLEY (W R) CORP & 52 & $2.49 \%$ & 50 & $1.29 \%$ \\
\hline PKG & PACKAGING CORP OF AMERICA & 53 & $2.45 \%$ & 43 & $2.77 \%$ \\
\hline CB & CHUBB CORP & 54 & $2.26 \%$ & 60 & $-0.29 \%$ \\
\hline ETN & EATON CORP & 55 & $1.79 \%$ & 54 & $0.54 \%$ \\
\hline CCE & COCA-COLA ENTERPRISES INC & 56 & $1.78 \%$ & 57 & $-0.06 \%$ \\
\hline UTX & UNITED TECHNOLOGIES CORP & 57 & $0.90 \%$ & 78 & $-2.50 \%$ \\
\hline POT & POTASH CORP SASK INC & 58 & $0.76 \%$ & 56 & $0.31 \%$ \\
\hline GS & GOLDMAN SACHS GROUP INC & 59 & $0.69 \%$ & 79 & $-2.52 \%$ \\
\hline TRP & TRANSCANADA CORP & 60 & $0.60 \%$ & 82 & $-2.55 \%$ \\
\hline AVP & AVON PRODUCTS & 61 & $0.53 \%$ & 61 & $-0.99 \%$ \\
\hline UPS & UNITED PARCEL SERVICE INC & 62 & $0.26 \%$ & 65 & $-1.50 \%$ \\
\hline SPG & SIMON PROPERTY GROUP INC & 63 & $0.24 \%$ & 75 & $-2.40 \%$ \\
\hline
\end{tabular}


Figure 1: Mean required rate of return by obligor's S\&P's credit grade

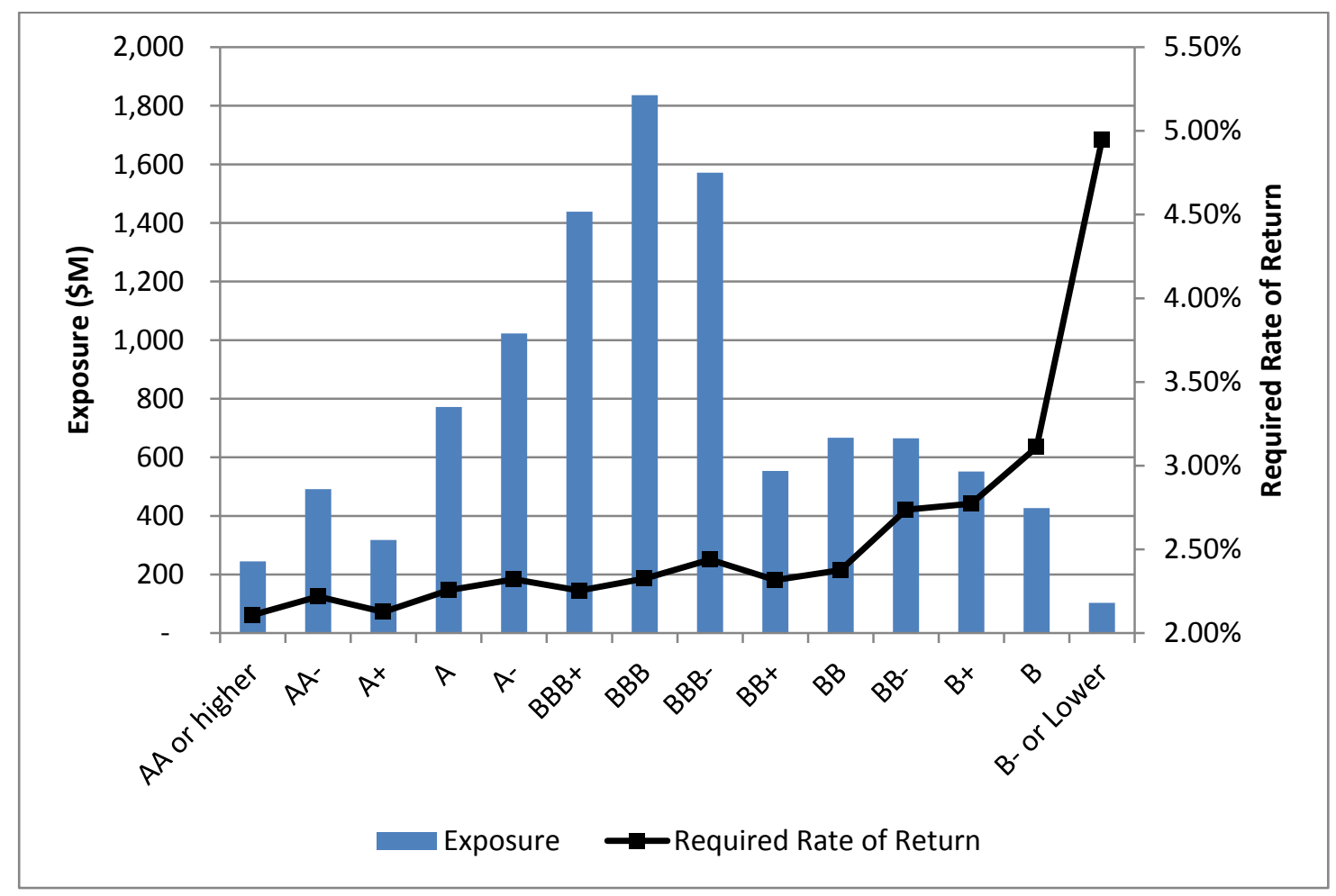


Figure 2: Scatter-plot of the profitability rankings based on the naive approach of using a single portfolio-wide hurdle rate against those from the use of instrument-specific hurdle rate.

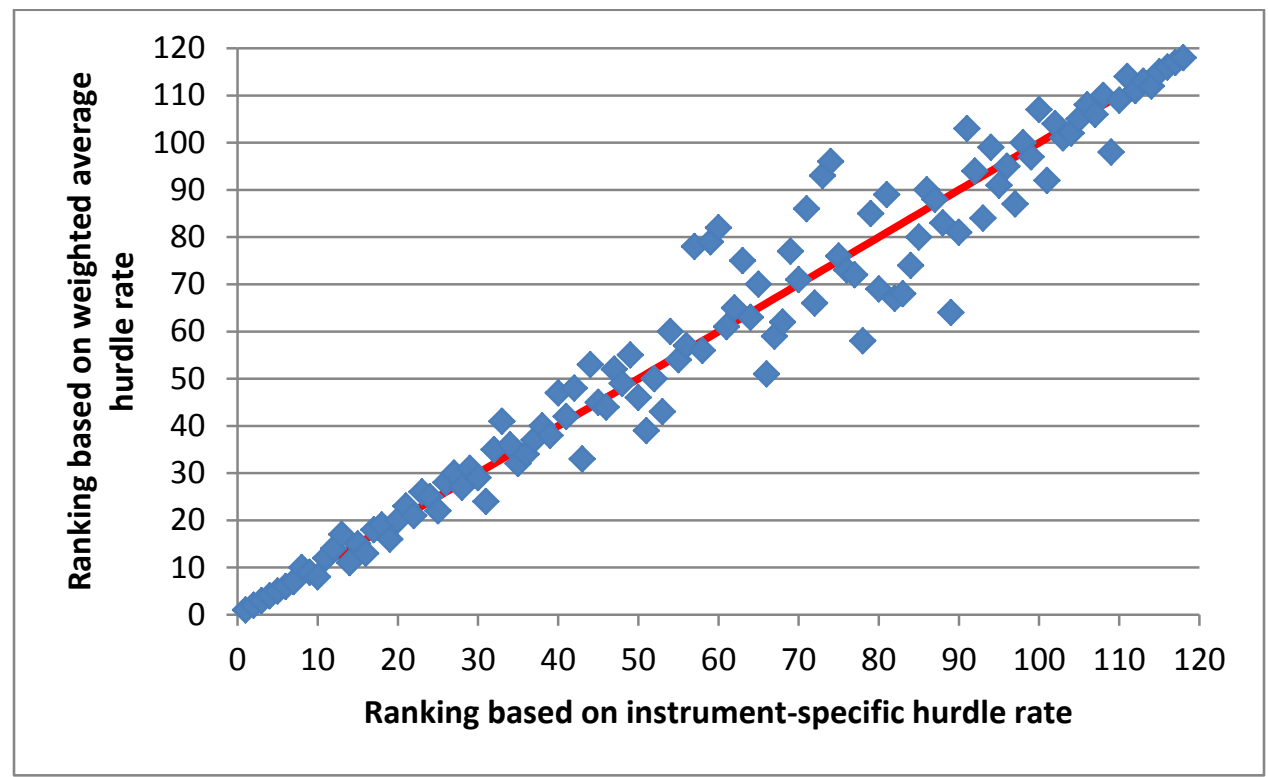




\section{Appendix A: Additional statistics of the sample portfolio}

Table A1: Number of debt issuers by industry sectors

\begin{tabular}{|c|c|c|}
\hline Sector & No. of observations & $\begin{array}{c}\% \text { of } \\
\text { observations }\end{array}$ \\
\hline Financial Sector & 151 & $19.24 \%$ \\
\hline Commercial Banks & 36 & $4.59 \%$ \\
\hline Funds & 60 & $7.64 \%$ \\
\hline Insurance & 32 & $4.08 \%$ \\
\hline Other Non-Bank FI & 17 & $2.17 \%$ \\
\hline Financial Services & 6 & $0.76 \%$ \\
\hline Business Service & 99 & $12.61 \%$ \\
\hline Oil \& Gas & 68 & $8.66 \%$ \\
\hline Oil \& Gas, Exploration & 60 & $7.64 \%$ \\
\hline Oil \& Gas, Refining & 8 & $1.02 \%$ \\
\hline Utilities & 46 & $5.86 \%$ \\
\hline Chemicals & 49 & $6.24 \%$ \\
\hline Retail \& Wholesale & 38 & $4.84 \%$ \\
\hline Consumer Durables & 36 & $4.59 \%$ \\
\hline Aerospace \& Defence & 41 & $5.22 \%$ \\
\hline Telecoms & 20 & $2.55 \%$ \\
\hline Automotive & 20 & $2.55 \%$ \\
\hline Equipment & 31 & $3.95 \%$ \\
\hline Machinery \& Equipment & 31 & $3.95 \%$ \\
\hline Rail \& Water Transportation & 16 & $2.04 \%$ \\
\hline Food Manufacturing & 15 & $1.91 \%$ \\
\hline Metal Products & 20 & $2.55 \%$ \\
\hline Paper Products & 11 & $1.40 \%$ \\
\hline Medical Services & 10 & $1.27 \%$ \\
\hline Mining & 17 & $2.17 \%$ \\
\hline Construction & 9 & $1.15 \%$ \\
\hline Entertainment & 8 & $1.02 \%$ \\
\hline Real Estate & 8 & $1.02 \%$ \\
\hline Hotels \& Restaurants & 11 & $1.40 \%$ \\
\hline Land Transport & 4 & $0.51 \%$ \\
\hline Air Transport & 3 & $0.38 \%$ \\
\hline Clothing Manufacturing & 9 & $1.15 \%$ \\
\hline Consumer Services & 4 & $0.51 \%$ \\
\hline Agriculture & 3 & $0.38 \%$ \\
\hline Automotive Rental & 2 & $0.25 \%$ \\
\hline Publishing & 1 & $0.13 \%$ \\
\hline Food Retail \& Wholesale & 2 & $0.25 \%$ \\
\hline Forestry & $\mathbf{1}$ & $0.13 \%$ \\
\hline Tobacco & 1 & $0.13 \%$ \\
\hline Total & 785 & $100 \%$ \\
\hline
\end{tabular}


Table A2: Breakdown of portfolio exposure by industry sectors

\begin{tabular}{|c|c|c|}
\hline Sector & $\begin{array}{l}\text { Exposure } \\
\text { (\$ million) }\end{array}$ & $\begin{array}{l}\text { Percent of } \\
\text { Exposure }\end{array}$ \\
\hline Financial Sector & $3,978.2$ & $24.8 \%$ \\
\hline Commercial Banks & $1,128.0$ & $7.0 \%$ \\
\hline Funds & $1,049.2$ & $6.5 \%$ \\
\hline Insurance & $1,034.7$ & $6.4 \%$ \\
\hline Other Non-Bank FI & 529.7 & $3.3 \%$ \\
\hline Financial Services & 236.6 & $1.5 \%$ \\
\hline Business Service & $1,292.1$ & $8.0 \%$ \\
\hline Oil \& Gas & $1,274.9$ & $7.9 \%$ \\
\hline Oil \& Gas, Exploration & $1,036.8$ & $6.5 \%$ \\
\hline Oil \& Gas, Refining & 238.1 & $1.5 \%$ \\
\hline Utilities & $1,245.1$ & $7.8 \%$ \\
\hline Chemicals & 811.0 & $5.1 \%$ \\
\hline Retail \& Wholesale & 748.0 & $4.7 \%$ \\
\hline Consumer Durables & 562.0 & $3.5 \%$ \\
\hline Aerospace \& Defence & 554.7 & $3.5 \%$ \\
\hline Telecoms & 479.6 & $3.0 \%$ \\
\hline Automotive & 455.6 & $2.8 \%$ \\
\hline Equipment & 448.0 & $2.8 \%$ \\
\hline Machinery \& Equipment & 443.0 & $2.8 \%$ \\
\hline $\begin{array}{l}\text { Rail \& Water } \\
\text { Transportation }\end{array}$ & 314.6 & $2.0 \%$ \\
\hline Food Manufacturing & 312.1 & $1.9 \%$ \\
\hline Metal Products & 290.0 & $1.8 \%$ \\
\hline Paper Products & 180.7 & $1.1 \%$ \\
\hline Medical Services & 170.5 & $1.1 \%$ \\
\hline Mining & 168.7 & $1.1 \%$ \\
\hline Construction & 162.6 & $1.0 \%$ \\
\hline Entertainment & 131.5 & $0.8 \%$ \\
\hline Real Estate & 120.0 & $0.7 \%$ \\
\hline Hotels \& Restaurants & 114.2 & $0.7 \%$ \\
\hline Land Transport & 96.0 & $0.6 \%$ \\
\hline Air Transport & 95.7 & $0.6 \%$ \\
\hline Clothing Manufacturing & 87.7 & $0.5 \%$ \\
\hline Consumer Services & 64.7 & $0.4 \%$ \\
\hline Agriculture & 46.2 & $0.3 \%$ \\
\hline Automotive Rental & 40.0 & $0.2 \%$ \\
\hline Publishing & 36.8 & $0.2 \%$ \\
\hline Food Retail \& Wholesale & 23.5 & $0.1 \%$ \\
\hline Forestry & 19.0 & $0.1 \%$ \\
\hline Tobacco & 11.7 & $0.1 \%$ \\
\hline Total & 14,778 & $100 \%$ \\
\hline
\end{tabular}


Table A3: Top 30 obligors by exposure

\begin{tabular}{|c|c|c|c|c|c|}
\hline \multirow[b]{2}{*}{ Ticker } & \multirow[b]{2}{*}{ Company Name } & \multicolumn{2}{|c|}{ Ratings } & \multirow[b]{2}{*}{ Industry } & \multirow{2}{*}{$\begin{array}{c}\text { Exposure } \\
(\$ M)\end{array}$} \\
\hline & & S\&P's & Moody's & & \\
\hline GS & GOLDMAN SACHS GROUP INC & A & A1 & Non-Bank FI & 130.7 \\
\hline WFC & WELLS FARGO \& CO & AA- & A2 & Commercial Bank & 99.5 \\
\hline BNS & BANK OF NOVA SCOTIA & AA- & Aa1 & Commercial Bank & 99.5 \\
\hline $\mathrm{TD}$ & TORONTO DOMINION BANK & AA- & Aaa & Commercial Bank & 99.5 \\
\hline AXP & AMERICAN EXPRESS CO & $\mathrm{BBB}+$ & A3 & Finance & 97.6 \\
\hline WMT & WAL-MART STORES INC & AA & Aa2 & Retail \& Wholesale & 94.3 \\
\hline AFL & AFLAC INC & A- & A3 & Insurance & 74.1 \\
\hline $\mathrm{COP}$ & CONOCOPHILLIPS & A & A1 & Oil \& Gas, Refining & 71.1 \\
\hline DFS & DISCOVER FINANCIAL SVCS INC & BBB- & Ba1 & Finance & 65.8 \\
\hline ADP & AUTOMATIC DATA PROCESSING & AAA & Aaа & Business Service & 64.9 \\
\hline KFT & KRAFT FOODS INC & BBB & Baa2 & Food Manufacturing & 63.3 \\
\hline ICE & INTERCONTINENTALEXCHANGE INC & & & Non-Bank FI & 57.5 \\
\hline UTX & UNITED TECHNOLOGIES CORP & A & A2 & Automotive & 56.4 \\
\hline $\mathrm{ABT}$ & ABBOTT LABORATORIES & AA & A1 & Chemicals & 56.0 \\
\hline DOW & DOW CHEMICAL & BBB & Baa3 & Chemicals & 55.1 \\
\hline BLK & BLACKROCK INC & $\mathrm{A}+$ & A1 & Non-Bank FI & 54.6 \\
\hline UAL & UNITED CONTINENTAL HLDGS INC & B & B3 & Air Transport & 52.5 \\
\hline $\mathrm{CB}$ & CHUBB CORP & $\mathrm{A}+$ & A2 & Insurance & 52.0 \\
\hline ORCL & ORACLE CORP & A & A1 & Business Service & 51.1 \\
\hline TGT & TARGET CORP & $\mathrm{A}+$ & A2 & Retail \& Wholesale & 50.4 \\
\hline WLP & WELLPOINT INC & A- & Baa1 & Insurance & 48.5 \\
\hline $\mathrm{S}$ & SPRINT NEXTEL CORP & BB- & B2 & Telecoms & 48.5 \\
\hline NEE & NEXTERA ENERGY INC & A- & Baa1 & Utilities & 47.9 \\
\hline CVS & CVS CAREMARK CORP & $\mathrm{BBB}+$ & Baa2 & Retail \& Wholesale & 47.8 \\
\hline $\mathrm{CNO}$ & CNO FINANCIAL GROUP INC & $\mathrm{B}^{+}$ & $\mathrm{B} 2$ & Insurance & 47.2 \\
\hline HON & HONEYWELL INTERNATIONAL INC & A & A2 & Automotive & 47.0 \\
\hline SO & SOUTHERN CO & $\mathrm{A}$ & Baa1 & Utilities & 47.0 \\
\hline LMT & LOCKHEED MARTIN CORP & A- & Baa1 & Automotive & 46.7 \\
\hline SU & SUNCOR ENERGY INC & $\mathrm{BBB}^{+}$ & Baa2 & Oil \& Gas, Refining & 46.7 \\
\hline VLO & VALERO ENERGY CORP & BBB & Baa2 & Oil \& Gas, Refining & 45.8 \\
\hline \multicolumn{5}{|c|}{ All Other Exposure } & $12,858.9$ \\
\hline \multicolumn{5}{|c|}{ Total } & $14,778.0$ \\
\hline
\end{tabular}

